\title{
EL ESPAÑOL DE HONDURAS A TRAVÉS DE SU BIBLIOGRAFÍA
}

Este trabajo presenta, como introducción, la situación de los estudios del español de Honduras en el contexto del área centroamericana. En la parte central se comentan los estudios más importantes sobre el español de Honduras y se muestran sus características fonéticas, morfosintácticas y léxicas, señaladas en los trabajos reseñados. Estas características constituirán algunas de las constantes del español de Honduras y podrían servir como elementos a considerar en trabajos posteriores. Finaliza con una exhaustiva bibliografía y un breve resumen del contenido de los trabajos más significativos. No se comentan los artículos muy específicos, como por ejemplo los que analizan la etimología de una palabra, ni los que tratan cuestiones generales del origen y evolución del castellano. Los textos que no hemos podido consultar llevan un asterisco a la izquierda del apellido del autor. De los abundantes libros de texto y lectura de educación primaria y media, sólo hemos incluido en la bibliografía aquellos que hacen alguna observación sobre el habla hondureña.

\section{Estudios del español de Centroamérica}

Los estudios del español de América han tenido un constante desarrollo. Hasta mediados del presente siglo han dominado los trabajos fonéticos y lexicográficos; en las dos últimas décadas, los fonológicos, y a partir de los ochenta han comenzado a publicarse algunos trabajos morfosintácticos. En general, los estudios del español de Centroamérica han seguido los pasos del español de América, aunque con notorio retraso. En el caso de Honduras, los estudios de R. J. Cuervo sirvieron de guía a Alberto Membreño, y en Costa Rica, a Gagini. 
Hasta la década de los cincuenta dominaron, en la región, las recopilaciones de vocabularios nacionales y "autóctonos" publicados bajo los títulos de hondureñismos, nicaragüesismos, . . con los subtítulos de provincialismos o barbarismos del país respectivo. En estos trabajos lexicográficos alternan las palabras del español que han tenido alguna variación en el significante o en el significado con las voces indígenas. Las variaciones fonéticas más usuales son aféresis, prótesis y epéntesis de vocales y, en algunos casos, de consonantes; metátesis y cambios de un fonema por otro, debidos a sonorizaciones, ensordecimientos, asimilaciones y disimilaciones, registradas tanto en América como en España. En los cambios semánticos dominan aquellos que han restringido su significación por especialización o la han ampliado adquiriendo nuevas acepciones. Los avances en los estudios de la dialectología del español de América y España han mostrado que estos diccionarios y vocabularios incluyen como "autóctonas" un gran número de voces que se usan con la misma variación fonética o significación en otras áreas dialectales del español. Ésta fue la principal crítica que Menéndez Pidal ${ }^{1}$ hizo a la primera edición de Hondureñismos de Alberto Membreño. La metodología utilizada en la recopilación de datos se caracterizó por el dominio de informantes de avanzada edad y la selección de áreas y poblaciones rurales en detrimento de las urbanas. Esta metodología provocó que estos diccionarios y vocabularios estén repletos de arcaísmos, regionalismos, localismos rurales, barbarismos e indigenismos. Esta visión conservadora del lenguaje en estos trabajos lexicográficos ha privado por muchos años a los países del área de diccionarios que muestren el léxico del habla estándar de cada país. Los primeros diccionarios del español del área se publicaron en 1892 y fueron los de A. Batres Jáuregui, Provincialismos de Guatemala, y de Carlos Gagini, Diccionario de costarriqueñismos. Tres años después publica Alberto Membreño Hondureñismos. Vocabulario de los provincialismos de Honduras. En 1933 aparece "Modismos panameños' de Celestino Mangado y en 1939 el Diccionario de nicaragüesismos de H. A. Castellón. El Salvador carece de un diccionario general, aunque cuenta con uno de quechuismos y varios de nahuatlismos ${ }^{2}$.

${ }^{1}$ R. Menéndez Pidal, "Hondureñismos de Membreño: nota crítica", Revista Crítica de Historia y Literatura Españolas, Portuguesas e Hispanoamericanas, Madrid, 1896, núm. 1, 75.

${ }^{2}$ Los diccionarios generales más importantes por países son: PANAMÁ: Celestino Mangado, "Modismos panameños", BAPaL, 7 (1933), 73-124; Miguel AMado, "El lenguaje en Panamá', BAAL, 14 (1945), 641-686 y 18 
A finales de la década de los cuarenta aparecen los primeros estudios sistemáticos de algunos aspectos fonéticos del español hablado en Panamá, Costa Rica, Nicaragua, El Salvador y Guatemala. En el caso del español de Honduras, no se publican los dos primeros estudios sistemáticos del fonema /s/ hasta $1983^{3}$. Destacan en las investigaciones fonéticas del español de Panamá los trabajos de Stanley L. Robe, E. Alvarado de Ricord y H. Cedergren $^{4}$. Por Costa Rica: Chavarría-Aguilar, A. Agüero, J.

(1949), 339-388; Luisa Aguilera Patiño, "Diccionario de panameñismos", BAAL, 20 (1951), 405-506; A. Revilla Agüero, Panameñismos, Roysa, Panamá, 1976; y Lenguage popular panameño, USMA, Panamá, 1982; COSTA RICA: Carlos Gagini, Diccionario de costarriqueñismos (I ${ }^{a}$ ed. 1892), San José, 1979; Juan Fernández Ferraz, Nahuatlismos de Costa Rica; ensayo lexicográfico acerca de las voces mejicanas que se hallan en el habla corriente de los costarricenses, Tipografía Nacional, San José, 1892; NICARAGUA: H. A. Castellón, Diccionario de nicaraguanismos, Managua, 1939; Alfonso Valle, Diccionario del habla nicaragüense, La Nueva Prensa, Managua, 1948; Carlos Mántica, El habla nicaragüense, EDUCA, San José de Costa Rica, 1973; HONDURAS: Alberto Membrẽ̃o, Hondureñismos. Vocabulario de los provincialismos de Honduras. (I ${ }^{\text {a }}$ ed. 1895), Guaymuras, Tegucigalpa, 1982; Carlos IzaGuirre, "Hondureñismos: vocablos, giros y locuciones más corrientes usadas en Honduras", $B A H o, 1$ (1955), 59-123; GUATEMAla: Antonio Batres Jáuregui, Provincialismos de Guatemala, Guatemala, 1892; Lisandro Sandoval, Semántica guatemalense o Diccionario de guatemaltequismos, 2 ts. Guatemala, 1941-1942; JORGE LUIS ARRIOLA, Pequeño diccionario etimológico de voces guatemaltecas, $2^{\text {a }}$ ed. Ministerio de Educación, Guatemala, 1954; Daniel ARMas, Diccionario de la expresión popular guatemalteca, $2^{\text {a }}$ ed., Piedra Santa, Guatemala, 1982; EL SALVADOR: Es el único paîs que no tiene un diccionario general del español. Los diccionarios existentes se orientan exclusivamente a los indigenismos: Alberto Membreño, Nombres geográficos de la República de El Salvador, Ignacio Escalante, México, 1908; Santiago I. Barberena, Quicheísmos, San Salvador, 1894; Pedro Gerffroy Rivas, El español que hablamos en El Salvador, Ministerio de Educación, San Salvador, 1975 (esta última obra, a pesar del título, estudia exclusivamente palabras del náhuatl); EnRiQue E. TOVAR, "Contribución al estudio del lenguaje salvadoreño", $B I C C, 3$ (1948). Es importante para el estudio léxico del espanol de Centroamérica la obra de Francisco J. Santamaría, Diccionario de mejicanismos, $3^{\text {a }}$ ed. Porrúa, México, 1978. Santamaría recoge las palabras y significados de los principales diccionarios centroamericanos citados.

${ }^{3} \mathrm{~J}$. M. LIPSKI, "Reducción de / $s /$ en el español de Honduras", $N R F H$, 32 (1983), 272-288; y A. L. LóPEz SCOTT, A sociolinguistic analysis of $/ s /$ variation in Honduras, tesis, University of Minnesota, 1983.

${ }^{4}$ STanley L. Robe, " $L$ y $-r$ implosivas en el español de Panamá", NRFH, 2 (1948), 272-275; "Algunos aspectos históricos del habla panameña", NRFH, 7 (1953), 209-220; The Spanish of rural Panamá, major dialectal features, tesis, University of California, Berkeley, 1960; Pedro I. Cohen, "Apuntes sobre la pronunciación del fonema /s/ en Panamá", Estudios, Instituto Nacional de Panamá, 2 (1964), 86-92; Estudios de lingüistica descriptiva: temas 
Wilson, S. Berk-Selingson y M. A. Selingson ${ }^{5}$. Por Nicaragua: H. Lacayo y Juan M. Lipski ${ }^{6}$. El español de El Salvador cuenta con los excelentes trabajos de D. Lincoln Canfield ${ }^{7}$ y el habla guatemalteca con los estudios de Richard L. Predmore, D. L. Canfield y Manuel Alvar 8 .

Muy escasos resultan, todavía, los trabajos sobre aspectos sintácticos del español de América. No obstante, han recibido un fuerte impulso gracias al Proyecto de estudio coordinado de la norma lingüistica culta de las principales ciudades de Iberoamérica y de la Peninsula Ibérica aprobado en enero de 1966. Se publican, en 1977, los primeros resultados en un volumen titulado Estudios sobre el español hablado

panameños, Universidad de Panamá, Panamá, 1971; E. Alvarado de Ricord, El español de Panamá: estudics fonético y fonológico, Edit. Universitaria, Panamá, 1971; H. CEDERgren, The interplay of social and linguistic factors in Panamá, tesis doctoral, Cornell University, Ithaca, NY, 1973; "En torno a la variación de la $s$ final en Panamá; análisis cuantitativo", Corrientes actuales en la dialectología del Caribe hispánico: Actas de un Simposio, ed. Humberto López Morales, Universidad de Puerto Rico, Río Piedras, 1978, pp. 35-49.

5 Oscar Chavarría-Aguilar, "The phonemes of Costa Rican Spanish", Lan, 27 (1951), 248-253; A. Agüero, El español de América y Costa Rica, Antonio Lehmann, San José de Costa Rica, 1962; “El español de Costa Rica y su atlas lingüístico", $P F E$, t. 1, pp. 135-152; J. 'WILSON, $A$ generative phonetical study of Costa Rican Spanish, tesis, University of Michigan, 1971; S. BERKSelingson y M. A. Selingson, "The phonological correlates of social stratification in the Spanish of Costa Rica", Lingua, 46 (1978), 1-28; S. BERKSELINGSON, Phonological variation in synchronic/diachronic sociolinguistic context: the case of Costa Rican Spanish, tesis doctoral, University of Arizona, Tempe, 1979.

${ }^{6} \mathrm{H}$. LaCayo, "Apuntes sobre la pronunciación del español de Nicaragua" , H, 37 (1954), 267-268; Cómo pronuncian el español en Nicaragua, Universidad Iberoamericana, México, 1962; J. M. LIPSKI, " $/ S /$ in the Spanish of Nicaragua"', Aparecerá en Orbis.

7 D. Lincoln CANField, "La pronunciación del español en El Salvador", Comunicaciones Ael Instituto de Investigaciones Cientificas, San Salvador, 2 (1953), 28-32; "Andalucismos en la pronunciación salvadoreña", $H, 36$ (1953), 3233; "Observaciones sobre el español salvadoreño", Fil, 6 (1960), 29-76; Spanish pronunciation in the Americas, University of Chicago, Chicago-London, 1981, pp. 52-54. Para Costa Rica véanse las pp. 39-41, Panamá, pp. 67-69, Nicaragua, pp. 65-66; J. M. LIPSKI, "Central American Spanish in the United States; the case of El Salvador". Ponencia presentada en el simposio El español en los Estados Unidos, Indiana University, aparecerá en Actas.

${ }^{8}$ Richard L. Predmore, "Pronunciación de varias consonantes en el español de Guatemala", $R F H, 7$ (1945), 277-280; D. Lincoln Canfield, "Guatemalan $r r$ and $s$ : a recapitulation of Old Spanish sibilant gradation", FSUS, 3 (1951), 49-51; Manuel AlVar, "Encuestas fonéticas en el suroccidente de Guatemala", LEA, 2 (1980), 245-287. 
en las principales ciudades de América ${ }^{9}$. En él se analizan diferenies aspectos sintácticos del habla de San Juan de Puerto Rico, México, Caracas, Buenos Aires y Santiago de Chile. Hay una gran escasez de trabajos morfosintácticos sobre el español de Centroamérica, exceptuando los sufijos derivativos. Aún es imprescindible, para tener una visión del español centroamericano, la consulta de la Sintaxis hispanoamericana de Ch. E. Kany (1945), basada en textos literarios. El español de Honduras, más concretamente el habla de Tegucigalpa, se estudia en el trabajo de H. L. Van Wijk, "Algunos aspectos morfológicos y sintácticos del habla hondureña" 10 . Abundan los trabajos sobre sufijos del español y de las lenguas indígenas. Destaca, por ser un trabajo sobre toda el área centroamericana, excepto Panamá, el estudio de Gary E. A. Scavnicky (1974) "Los «sufijos» no españoles y las innovaciones sufijales en el español centroamericano". Scavnicky11 estudió en el habla guatemalteca el sufijo - al y Max Leopold Wagner ${ }^{12}$ el sufijo -eco para defectos físicos en toda Hispanoamérica. A pesar de estos estudios y otros no señalados, sigue siendo válida, sobre todo para Centroamérica, la observación que Lope Blanch hizo, hace dos décadas, de la escasez de estudios gramaticales sobre el español de América:

Por supuesto que sería de desear que se prestara mayor atención de la que se les ha concedido hasta ahora a los fenómenos gramaticales. En muchos de los trabajos publicados últimamente se atiende sólo a los hechos fonéticos y léxicos del idioma, en tanto que la estructura gramatical, columna vertebral de la lengua, queda en el olvido ${ }^{13}$.

Una valoración general de los estudios sobre el español de Centroamérica muestra, por un lado, el gran camino que falta por recorrer para igualarse con otras áreas de América y, por otro, el desequilibrio de estudios dentro de la propia área. El español

${ }^{9}$ Juan M. Lope Blanch (ed.), Estudios sobre el español de las principales ciudades de América, UNAM, México, 1977.

${ }^{10}$ BdFS, 20 (1968), 3-16.

11 R. L. Predmore, "El sufijo -al en el español de Guatemala", $N R F H$, 6 (1952), 140-144; Gary E. A. SCaVnicky, "El sufijo -al en el español centroamericano", EAc, 1974, núm. 28, 18-21.

${ }^{12}$ M. L. WAGNER, "El sufijo hispanoamericano -eco para denotar defectos físicos y morales", NRFH, 4 (1950), 105-114.

13 Juan M. Lope Blanch, El español de América, Alcalá, Madrid, 1968, p. 125. 
de Panamá y Costa Rica cuenta, en estas dos últimas décadas, con mayor número de estudios fonéticos que el resto de los países del área. El habla guatemalteca y salvadoreña contaba ya con los estudios de D. L. Canfield y R. L. Predmore, añadiendo, en el caso de Guatemala, el reciente trabajo de Manuel Alvar ${ }^{14}$ sobre las actitudes lingüísticas en Guatemala. Las hablas de Honduras y de Nicaragua siguen siendo las que cuentan con menos estudios, si bien, en el caso de Honduras, se publicaron a partir de 1983 algunos estudios fonéticos y léxicos.

\section{LOS ESTUdIOS FONÉTICOS DEL ESPAÑOL DE HONDURAS}

Los estudios fonético-fonológicos del español de Honduras pueden dividirse en dos etapas. La primera se inicia a finales del siglo XIX, año de 1895, con la publicación de Hondureñismos de A. Membreño, y termina en 1982. Esta etapa se caracteriza por la inexistencia de estudios propiamente fonéticos. No obstante, un análisis de los barbarismos que incluyen los diccionarios y vocabularios de "hondureñismos" publicados en esta etapa muestra ciertos fenómenos fonéticos del español rural de Honduras y uno que otro del habla urbana. Otra fuente de información más directa son algunos artículos pedagógicos publicados en la Revista de Educación Pedagógica y contados libros de texto. En ambas fuentes se incluyen listados de palabras mal pronunciadas, poniendo al lado la forma correcta del español culto. Esta etapa termina con la publicación de los trabajos de D. L. Canfield y H. L. Van Wijk. La segunda etapa se inicia en 1983 con la publicación de trabajos específicos del habla hondureña: "Reducción de la /s/ en el español de Honduras", de J. M. Lipski y la tesis de doctorado de A. L. López Scott, "A sociolinguistic analysis of/s/ variation in Honduran Spanish".

La primera etapa de los estudios fonético-fonológicos del español de Honduras carece, como ya se señaló, de trabajos específicos. Se presentan aquí las principales constantes fonéticas del español de Honduras, que se obtienen por una parte del análisis sistemático de artículos, vocabularios y diccionarios de hondureñismos publicados entre 1895 y 1982 y por otra de las observacio-

\footnotetext{
${ }^{14}$ Además del artículo señalado al final de la nota 8 de este trabajo, véase Manuel Alvar, Hombre, etnia, estado (actitudes lingüísticas en Hispanoamérica), Gredos, Madrid, 1986. Para el caso de Guatemala, véase cap. 3, pp. 74-92.
} 
nes del autor de este artículo. Los fenómenos que enumeramos primero tienen cierta vigencia en las zonas rurales de Honduras y en las zonas periféricas de las ciudades de San Pedro Sula y Tegucigalpa. También se señala si el fenómeno se da en la gente culta de las dos ciudades señaladas. Las obras y trabajos consultados han sido: Hondureñismos (1895) de A. Membreño; "Provincialismos y barbarismos hondureños" (1906) de E. Martínez López; "Más hondureñismos"' (1914) de José Francisco Elvir; Apostillas sobre gramática y lenguaje (1945) de Rubén Barahona; "Idioma nacional, símbolo de la patria" (1945) de V. F. Ardón y "Programa de Castellano de Primer Curso...' (1954) de Carlos R. Cortés. Los resultados son:

1) $e$ átona $>i$, en muchos de los casos por asimilación o disimilación: intrinsico, dispertar, dispensa, indilgar, distiempo, dishora, alfiñique, perdidizo, cinturión, manijar, miñique y titunte.

2) $i$ átona $>e$ : diceres 'decires', femenistas, desentería, meopia, menistro, bacenilla, erritado, escrebir, venistes, herver y herve. También se oyen en zonas rurales: vesita, melitar, cevil y prencepal. De ellos herve se oye en personas cultas.

3) o pretónica o postónica $>u$ : mausuleo, fechuría y muchila. Barahona señala también culumpio, se culumpió y culumpiarse. Estas tres últimas palabras las pronuncian con $u$ incluso las personas cultas.

4) Cambio, opuesto al anterior, $u$ pretónica o postónica $>0$ : cañafístola, coyontura y sepoltura.

5) $a>e$ : resurar, especies, frezada 'frazada' y estilla.

6) $o>e$ : traste, trastes, dector y fósfero. Se ha generalizado en Honduras la oposición semántica traste 'cualquier objeto de cocina' / trasto 'cualquier objeto viejo o grande de la casa'. Semejante es la oposición de los plurales trastes/trastos.

7) Cambio de $e$ en hiato por $i$ : acordión, antiojos, maistro, vigiar y todos los verbos terminados en -ear. Las pronuncian con $i$ la mayoría de personas cultas. La tendencia a crear diptongos donde hay hiato hace que la $o>u$ : almuada. No registran pueta ni cuete, generalizados en zonas rurales y urbanas, e incluso en personas cultas. Este doblete fonético está facilitando la especialización semántica de algunas palabras como maistro 'maestro de obras, maestro zapatero', etc. / maestro 'maestro de escuela, un buen profesor universitario', etc. Poetalpueta: el segundo significante se utiliza para denominar a un poetastro. 
8) Abundan los ejemplos de eliminación de diptongos por pérdida de una de las vocales o por elegir el hablante la vocal de apertura intermedia en la serie. Ejemplos: ie $>e$ : concencia, consetudinario, repartimento, arrenden, apreten y neva (estas dos últimas pronunciadas así incluso por personas cultas); io $>o$ : confesonario; $u i>i$ : gratitos; $u e>0$ : poble, troque, pañolito y volque.

9) Tendencia a crear diptongos por influencia de una palabra que se cree es la primitiva de la misma familia. De diente: dientera, dientón y dientudo. Las dos últimas las incluye el $D R A E$. La primera se oye en el habla de personas cultas.

10) Introducción de una vocal inexistente en la palabra y que, se supone, facilita la pronunciación: albiricias, desaveniencia, desatornillador e Ingalaterra. La segunda y tercera se oyen en la mayoría de personas cultas.

11) Fenómeno contrario es la eliminación de una vocal o de una sílaba: florcita, atol, comelitón, destrancar, metralladora, zuela, corografía, piecitos, piernita, comparencia y prestigitador. De ellas se oyen entre personas cultas: florcita, atol, piecitos y piernita.

12) Introducción de una consonante epentética: $g$ en aigre, cirgüelos y cirgüela; $n$ en inrompible; $s$ en convalescencia se oyen incluso entre estudiantes universitarios; $r$ en gurbia y petrimetre y las dos últimas casi generalizadas entre personas cultas. Especial mención debe hacerse por su generalización y frecuencia en sectores rurales y urbanos marginales la inclusión de una $/ y /$ epentética en las palabras que terminan en -ia: sandiya, sandiyal, Mariya, etc. También se da en la palabra veya. Es frecuente oír en Tegucigalpa, incluso entre personas cultas enchufle y rampla.

13) Un buen número de palabras muestran alternancias y modificaciones en la pronunciación de ciertas consonantes: $l>r$ en chirca 'colilla', arcancía, arquila, delantar y gradiolo; $r>l$ en santulón; $g>c$ en rengo, $b$ en burrión 'gorrión', $j[x]$ en cojollo; la $c>g$ en guancasgo "encuentro de dos santos en la guardarraya de dos pueblos' e intrínculis; la $h>c$ en alcaraca y alcaraquiento, $f$ en fundir y fierros, $j[\mathrm{x}]$ en joyada 'hoyada', juir, josco, jonda, jamaca, jumear y jurgar; $n>\tilde{n}$ en $\tilde{n} u$ $d o ; d>r$ en liriar y perigüeño; $l>d$ en diquidambo. Se oyen con cierta frecuencia en el ambiente universitario: gradiolo, cojollo, alcaraquiento, fierros, generalizada en Honduras 
con el significado de 'herramientas', nudo, suramericano, mayugar y pedrestre.

14) En la pronunciación de los grupos consonánticos tiende, en los sectores menos cultos, a perderse la primera consonante o vocalizarse en $i, u$. Ejemplos: $c c>i c$ en aición y faición; $c t>$ ut en perfeuto y autor, provocando en el Occidente de Honduras el doblete autor/actor para denominar al " experto en rituales y ceremonias"'. Como reacción opuesta suelen darse ultracorrecciones en palabras tales como aficción por afición, aficcionados por aficionados, actoridad por autoridad y actor por autor.

15) El grupo se lo pronuncia como $[k s]$ la mayoría de personas cultas [oksilasjón].

16) Se dan ciertas metátesis de vocales y consonantes: culecas, enjaguar, naide y riubarbo; fugral, cabresto, paderón, catálago y murciégalo. Se oyen con cierta frecuencia entre gente culta: culecas, enjaguar, grabeta y murciégalo.

17) Cambios de posición del acento: díceres, váguido 'vahído', páis, máis y paráiso. Estas dos últimas voces se oyen en algunas personas cultas. También se oyen con frecuencia: epígrama, hóstil, sáuco, etcétera.

18) La - $d$ en posición implosiva final de palabra, lo mismo que la $-x$ tienden, incluso entre las personas cultas, a no pronunciarse: paré, usté, amistá, soledá, reló.

Al final de la primera etapa aparecen referencias fonéticas al español de Honduras en notas dispersas a lo largo del artículo de D. L. Canfield "Observaciones sobre el español de El Salvador"'15. Éstas son:

a) Que el español de El Salvador en su fonetismo y en su léxico forma una unidad lingüística con el de Honduras y Nicaragua ${ }^{16}$.

${ }^{15}$ D. L. Canfield, "Observaciones sobre...", pp. 31, 41, 48, 51.

${ }^{16}$ Esta afirmación de D. L. Canfield que el español de El Salvador y Honduras forman una unidad por su fonetismo y su léxico es muy discutible. Creo que es cierta la semejanza fonética del habla salvadoreña con la de los departamentos hondureños de Valle, Choluteca, La Paz, Lempira, parte de Ocotepeque, Comayagua y Francisco Morazán, en especial el habla de Tegucigalpa. Hay sin embargo muchas diferencias entre el habla salvadoreña y el habla hondureña de los departamentos de Cortés, Atlántida, Colón, noroeste de Gracias a Dios y el departamento de Islas de la Bahía. El habla hondureña 
b) El diptongo eu de la palabra deuda, tanto en El Salvador como en Honduras, la mayoría la pronuncian [eud] y otros como [elpd], pero entre la clase obrera muchos convirtieron la $u$ en consonante velar: $[e \phi d],[e g d],[e k d]$.

c) La $s$ ante hie, y, $l l$ como en las hierbas, la $y$ se siente corno inicial y se pronuncia casi siempre $[\hat{y}]$, y la $s$ es $[h]$. La frase las llantas ya no sirven dio casi siempre [lah ŷantah ŷa no sirben].

d) En Tegucigalpa se oye, como en Guadalajara, México, la aparición de la nasal $n$ después de $s: \operatorname{dos}-n$, tres- $n$, adiós- $n$.

e) Otro rasgo bastante raro en el mundo hispanohablante es la tendencia ciceante en la articulación de las sibilantes. Se oye en Andalucía, en las costas de Venezuela y Colombia y en Honduras y Nicaragua.

D. L. Canfield ${ }^{17}$ reúne y sistematiza la información fonética del habla hondureña en su obra Spanish pronunciation in the Americas. Basándose en grabaciones que hizo en Tegucigalpa en el verano de 1952, muestra algunas tendencias y actitudes que se dan en el habla hondureña. Canfield reconoce que tiene poca información del habla de las ciudades de San Pedro y La Ceiba. Señala como tendencias generales del habla las siguientes:

$/ \mathrm{b}, \mathrm{d}, \mathrm{g} / \Rightarrow[\mathrm{b}, \mathrm{d}, \mathrm{g}]$ (después de otra consonante o semivocal). $/ \mathrm{s} / \Rightarrow[\mathrm{s}]$ o $[\theta]$

$-/ \mathrm{n} / \Rightarrow[\mathrm{y}]$ (en final de palabra antes de pausa o vocal)

$/ \mathrm{x} / \Rightarrow[\mathrm{h}]$

$/ \mathrm{l} / \mathrm{e} / \mathrm{y} / \Rightarrow[\mathrm{y}]$ o $[\mathrm{i}]$ y viceversa (día $\Rightarrow[$ díya $]$ )

$/ \overline{\mathrm{r}} / \Rightarrow[\overline{\mathrm{r}}]$

Como actitudes del habla hondureña señala las siguientes:

$$
\begin{aligned}
& -/ \mathrm{s} / \Rightarrow[\mathrm{h}] \text { o }[\mathrm{s}] \text { o }[\theta] \\
& -/ \mathrm{s} / \Rightarrow[\mathrm{z}] \text { o }[\mathrm{h}] \text { (antes de consonante) } \\
& / \mathrm{f} / \Rightarrow[\mathrm{p}] \text { o }[\mathrm{f}] \\
& -/ \mathrm{d} /-\Rightarrow[\mathrm{d}] \circ[\theta]
\end{aligned}
$$

de la Costa Atlántica es más avanzada que la de El Salvador y la de Tegucigalpa; pérdida de $-s$ final, aspiración de $s[\mathrm{~h}]$ entre vocales, velarización de $-n$ en posición final. En el léxico existen también notables diferencias. Hay una mayor penetración de anglicismos debido al inglés hablado desde finales de la Colonia española en Islas de la Bahía, y sobre todo a partir de 1906 con la llegada masiva de las compañías bananeras cuyas casas matrices se encuentran en Estados Unidos.

${ }^{17}$ D. L. Canfield, Spanish pronuntiation..., pp. 56-57. 
La segunda etapa en los estudios de la fonética del español de Honduras se inicia en 1983 con la publicación del artículo de Juan M. Lipski (1983) la "Reducción de la /s/ en el español de Honduras" y la tesis de doctorado de A. L. López Scott (1983) "A sociolinguistic analysis of /s/ variation in Honduran Spanish". J. M. Lipski publica en 1987 un estudio global titulado Fonética y fonología del español de Honduras. Es el primer estudio sistemático que, según el autor, abarca todo el territorio nacional y todas las clases sociales. Aplica los principios y la metodología de la corriente de la fonología natural de Hooper, derivada de la fonología generativa-transformacional. Analiza todas las vocales y las consonantes, en especial la /s/ y la $/ \mathrm{n} /$. Considera al español de Honduras, teniendo en cuenta su evolución consonántica, como medianamente avanzado. Al final de su estudio resume así las características fonético-fonológicas más importantes del habla hondureña:

1. Comportamiento de $/ \mathrm{l} / \mathrm{y} / \mathrm{r} /$ implosivas. Ocurren pocos casos de neutralización.

2. Comportamiento de /n/ final de palabra. Ocurre con frecuencia la velarización, aunque suele conservarse alguna articulación consonántica.

3. Realización de /d/ intervocálica. Suele conservarse con tenacidad la articulación fricativa, aunque se realice con una articulación muy ligera.

4. $/ \bar{r} /$ explosiva. Se articula siempre como vibrante múltiple y no hay tendencia a la asibilación o la velarización.

5. / $\mathrm{r} /$ implosiva en posición final absoluta. Se articula como vibrante simple o a veces múltiple, sin rasgos de asibilación.

6. Grupo /tr/. Apenas se articula como africada; suele mantenerse su integridad como grupo biconsonántico.

7. Realización de /y/. Tiene poca fricción y nunca se produce un rehilamiento; al contrario, puede desaparecer en muchos contextos intervocálicos.

8. Realización de /s/ implosiva. Se aspira con frecuencia en posición preconsonántica y aun en posición final absoluta, pero es raro que se pierda por completo. La aspiración en posición final prevocálica es menos generalizada, lo cual indica un proceso intermedio de evolución. Por otra parte la aspiración de /s/ inicial de palabra y entre vocales representa una innovación dentro del ámbito centroamericano que nada tiene que ver con el estado menos evolucionado de la fonología hondureña.

9. Realización de $/ \tilde{\mathbf{n}} /$. Suele articularse como consonante nasal palatal, y casi nunca se pierde la oclusión bucal. 
10. Realización de /ê/. Suele conservarse el elemento oclusivo.

11. Realización de /b/y/g/ entre vocales. Suelen mantenerse como fricativas.

12. $/ \mathrm{b} /, / \mathrm{d} / \mathrm{y} / \mathrm{g} /$ posconsonánticas. Normalmente se realizan como oclusivas.

13. Comportamiento de consonantes oclusivas en posición implosiva. La tasa de posteriorización es relativamente baja.

14. La pérdida ocasional de /s/final de palabra no ha resultado en un desdoblamiento fonológico en el sistemas vocálico.

15. Las vocales átonas mantienen su integridad fonética, dividiéndose siempre en cinco núcleos diferenciables ${ }^{18}$.

Si bien será motivo de otro trabajo, en mis registros aparecen algunos fenómenos fonéticos del español de Honduras, en especial del habla de Tegucigalpa, que, o no se han señalado, o se dan con mayor frecuencia de la señalada por Lipski:

1) En Honduras hay zonas de ceceo que abarcan ciudades importantes desde la época colonial española, como Trujillo. Son ceceantes incluso personas cultas universitarias y políticos nacidos en esas áreas que desde jóvenes emigraron a Tegucigalpa. Tengo registros de ceceo en casi todo el departamento de Colón, incluyendo su capital, Trujillo; la franja limítrofe de los departamentos de Francisco Morazán y El Paraíso, pueblos de La Venta, Maraita y Liure y puntos aislados del occidente de Honduras como Guajiquiro en el departamento de La Paz.

2) La / l/ en la terminación -illo, -illa no se pronuncia, incluso las personas cultas: cuchillo [kućío].

3) $\mathrm{La} / \mathrm{c} /$, al menos en el habla de Tegucigalpa, tiene dos realizaciones. La más usual es [ĉ] alveopalatal africada, con una ligera oclusión, pero personas cultas en contextos donde quieren impresionar al oyente (discursos, conferencias,

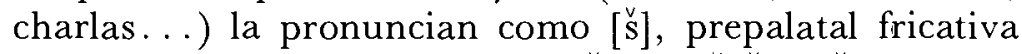
sorda: mucho, muchacho, ocho [múšo, mušáco, óso].

4) En Tegucigalpa, personas de nivel socioeconómico alto $y$ medio, con cierta frecuencia en conversaciones informales, asibilan la $/ \check{r} /$ en posición inicial y final y en algunas palabras donde aparece el grupo /tr/: rico, servir, nosotras [ $\stackrel{\mathrm{v} i c o}{\mathrm{~V}}$ servirư, nosótras]. Este fenómeno ha sido señalado, también

${ }^{18} \mathrm{~J}$. M. LIPSKI, Fonética y fonología del español de Honduras, Guaymuras, Tegucigalpa, 1987, pp. 131-132. 
por J. M. Lipski si bien creo oue es más frecuente y se da en más contextos de los que él señala. Es un fenómeno en franca expansión.

5) En la pronunciación de los grupos consonánticos se dan dos tendencias opuestas muy marcadas. En los niveles más bajos, tanto en zonas rurales como urbanas, la tendencia es a eliminar la primera consonante: $b t[\mathrm{t}], p t[\mathrm{t}] \ldots$ En los niveles medios y altos, la tendencia es a conservarlos pronunciando la primera consonante como sorda aún en el caso de que sea sonora: objeto, advertir [opxéto, akbertír].

A pesar de lo expuesto, la descripción fonética del habla hondureña tiene grandes vacíos. Está sin estudiar y caracterizar el habla de la costa Atlántica, en especial La Ciba, San Pedro Sula y Trujillo; de la costa Pacífica, Choluteca, y del occidente del país. No se han investigado los elementos suprasegmentales, en especial entonación y cantidad. Se necesitan, además, estudios sociolingüísticos del habla de Tegucigalpa, que desde los años sesenta hasta la fecha ha tenido una sorprendente inmigración.

\section{ESTUDIOS MORFOSINTÁCTICOS}

No existen propiamente estudios sintácticos del español de Honduras. Hay, sin embargo, algunos estudios morfológicos, en especial de los sufijos derivativos.

En su Sintaxis hispanoamericana Charles E. Kany ${ }^{19}$ señala algunas características del español de Honduras. Describe con mayor amplitud el voseo, las formas verbales y el uso de las preposiciones. Kany toma sus ejemplos, en el caso del habla hondureña, sólo de obras literarias. Las obras literarias hondureñas que consultó son: La heredad (1931) y Cuentos de lobos (1941) de Marcos Garías Reyes; La epopeya del campeño (s.f.) de Augusto C. Coello; Sombra (1940) de Arturo Martínez Galindo; Relatos nativos (1929) y El solterón (1929) de Arturo Mejía Nieto y Fábulas (1931) de Luis Andrés Zúñiga. La obra de Kany tiene como limitante haber trabajado sólo con textos literarios y, además, en el caso de Honduras, utilizó textos poco actualizados, incluso para el momento en que se publicó la obra.

19 Charles E. Kany, Sintaxis hispanoamericana, Gredos, Madrid, 1976, pp. $23,25,27,57,59,67-71$ ss. 
Gary E. A. Scavnick publica el artículo "Los "Sufijos» no españoles y las innovaciones sufijales en el español de Centroamérica". Divide el trabajo en cuatro apartados:

a) Breve historia de las lenguas y tribus aborígenes y actuales de la América Central.

b) Voces con desinencias indígenas, africanas o inciertas.

c) Voces cuyos sufijos pueden derivarse en España o en los idiomas indígenas.

d) Formaciones híbridas - raíz indígena y sufijo español-que ejemplifican usos comunes y usos innovadores ${ }^{20}$.

En este artículo la información sobre las lenguas y tribus de América Central es incompleta, en especial la referente a Honduras. Trata de explicar en cada sufijo su origen y significación e incluye en cada uno de ellos palabras con dicho sufijo registradas en los diccionarios de español de los respectivos países del área centroamericana.

H. L. Van Wijk ${ }^{21}$ publica "Los gentilicios hondureños". En este trabajo registra el nombre de 130 ciudades, villas y pueblos. Los resultados de la investigación son:

\begin{tabular}{ll}
\hline Sufijos & Lugares \\
\hline -eño, & $74(57 \%)$ \\
-ense, & $29(22.3 \%)$ \\
-ano, & $15(11.5 \%)$ \\
-eco, & $5(3.9 \%)$ \\
-ino, & $4(3.1 \%)$ \\
-ero, & $2(1.5 \%)$ \\
- -́n, & $1(0.7 \%)$ \\
\hline
\end{tabular}

Señala, además, que el hondureño no es muy dado en la conversación al uso de los gentilicios, sustituyéndolos por expresiones como say de Comayagua o soy comayagua. Todos los sufijos son de origen latino menos -eco que es del náhuatl. Contrariamente a lo que ocurre en España o en Chile, no existen en Honduras regiones que tengan preferencia especial por el uso de determinado sufijo.

${ }^{20}$ BICC, 29 (1974), p. 1.

${ }^{21}$ H. L. VAN WIJK, "Los gentilicios hondureños", HIEH., pp. 593-603. 
El estudio morfosintáctico más completo hasta la fecha del habla hondureña es el de H. L. Van Wijk, "Algunos aspectos morfológicos y sintácticos del habla hondureña'. Según el autor, los datos fueron recogidos en Tegucigalpa y "otras localidades de la República" (no las especifica) en los meses de septiembre y octubre de 1961. En el trabajo analiza algunos aspectos del artículo definido, el voseo, el verbo y sus perífrasis, algunos adverbios, las preposiciones y la formación nominal. El propio autor, al final de su trabajo, resume así las características morfológicas más importantes del habla hondureña:

. . los numerosos arcaísmos de construcción y en las intocables voces nuevas, el uso mayoritario de los sufijos -ada, -al, -ero, -era, -ón, -(a)zón y -dera, muy empleado este último para indicar actos repetidos o prolongados. Otras características notables son la tendencia a usar adverbialmente el adjetivo, el uso de ir + gerundio como perífrasis perfectiva, el frecuente empleo del auxiliar volar en locuciones perifrásticas y el verbo saber como mero auxiliar de aspecto unitario o como equivalente de "poder" o "gustar", el uso popular, relativamente frecuente, del diminutivo -illo asociado con -ito en adjetivos y adverbios y el empleo del sufijo náhuatl -eco en la derivación de gentilicios y en la formación de adjetivos despectivos que indican defectos ${ }^{22}$.

M. Beatriz Fontanella al comentar este trabajo en su obra La lengua española fuera de España señala que "el hecho de que el autor se haya basado no sólo en la observación del habla coloquial, sino también en obras literarias, sin precisar en cada caso si los ejemplos son orales o literarios, disminuye marcadamente su valor' '23.

Los sufijos derivativos, especialmente los aumentativos y diminutivos, son el aspecto morfológico del español de Honduras más estudiado. Además del trabajo de Van Wijk, "Los gentilicios hondureños", A. Hernández y M. J. Rivera (1971) en “El uso de los sufijos del habla hondureña' registran un buen número de palabras con los sufijos -era, -ero, -al, -ina, -rí, -ada, -oso, -udo, -ingo, -eco, -ón, -illa y -encía. E. Pineda Urbina, E. Benítez, y R. Guzmán (1972 ?) realizaron un trabajo sobre el uso de aumentativos y diminutivos en ciento cincuenta jóvenes estudiantes de educación media de las ciudades de Ocotepeque y Olanchito. Los

${ }^{22}$ H. L. VAN WIJK, "Algunos aspectos...", p. 16.

${ }^{23}$ María Beatriz Fontanella de Weinberg, La lengua española fuera de España, América, Canañas, Filipinas, judeoespañol, Paidós, Buenos Aires, 1976, p. 97. 
sufijos aumentativos más utilizados fueron: -ote $(57.6 \%)$, -ón $(22.3 \%)$ y -ozo $(4.3 \%)$. No llegan al $1 \%$ de frecuencia: -ísimo, -otote y -arión. Según el mismo trabajo los diminutivos con mayor frecuencia de uso fueron -ito $(81.54 \%)$ e -illo (1.5\%). No llegan al $1 \%$ de frecuencia de uso: -ecillo, -in, -itíto y -oncillo. Tanto estos dos trabajos como el de Gary E. A. Scavnick muestran un uso abrumador de sufijos derivativos del español. De procedencia no española aparece únicamente -ingo ${ }^{24}$.

Han sido estudiados brevemente algunos aspectos verbales del habla de Tegucigalpa en la tesis Uso regional del verbo en Honduras de M. A. González y N. L. Martínez (1972 ?). En este trabajo domina el estudio semántico sobre el morfosintáctico. Muestra la ampliación de significado en el habla de Tegucigalpa de muchos verbos que pasan a ser palabras comodín (verbis multi). Sólo en el capítulo 4 incluye algunos ejemplos de mal uso de modos, tiempos, número, persona, verbos transitivos e intransitivos. Elisa Martínez (1976) en su trabajo El vocabulario escolar investigó la frecuencia de uso de sustantivos, adjetivos y verbos de los alumnos de educación media de trece centros educativos de Tegucigalpa. En los verbos señala cuáles son los más usados, así como sus tiempos. Domina el uso de los tiempos del modo indicativo.

Existen algunos artículos y glosarios de poca extensión donde se hacen referencias a aspectos morfosintácticos del habla hondureña. Destacan: Apostillas del lenguaje de Rubén Barahona (1945) en el que analiza algunas palabras y locuciones utilizadas en Honduras "en forma impropia e incorrecta", Eliseo Pérez Cadalso (1988) sobre el "dequeismo" y V. F. Ardón (1954) sobre pluralización del verbo haber y uso incorrecto de algunas preposiciones, adverbios y grados del adjetivo.

${ }^{24} \mathrm{El}$ sufijo -ingo (-a) es considerado por GARY E. A. SCAVnicky (art. cit., pp. 18-19) como "de origen africano o indígena". Se utiliza en formaciones nuevas para denotar "acción y efecto", cierto sentido despectivo aplicado a personas y otros significados. No se considera aquí el sufijo -eco como proveniente del náhuatl, sino del español. La tesis de su procedencia náhuatl fue sustentada por Max L. Wagner (art. cit.). Jorge A. SuÁrez en su artículo "Indigenismos e hispanismos, vistos desde la Argentina", $R P h, 20$ (1966-67), pp. 68,70 , mostró su procedencia española, basándose en que -ic del náhuatl no da -eco en español y que las formas en -eco cubren áreas mayores que las de influencia náhuatl. J. M. LOPE BlANCH ("Sobre el origen del sufijo -eco, como desigmador de defectos", $H H M, 305-312$ ), llega a la misma conclusión que Suárez, basándose en la presencia de palabras con sufijo -eco en el español peninsular y en que los préstamos del náhuatl al español con sufijo - $(t) i c$ en su mayoría han dado -te y no -eco. 
No obstante los trabajos comentados, el español de Honduras no ha sido estudiado sintácticamente. Es prioritario el estudio del orden oracional, los periodos de subordinación, la concordancia temporum y la concordancia sujeto-verbo y verbo-objeto directo. Son notorios los cambios de orden en el español escrito sin cumplir ese cambio funciones específicas de significación, periodos subordinados incompletos, discordancia de tiempos en oraciones coordinadas, y subordinadas y restos de concordancia del español medieval del verbo con el objeto directo en frases lexicalizadas.

\section{EsTUdIOS LÉXICOS}

En este apartado se reseñan los diccionarios generales de hondureñismos, los vocabularios regionales y locales, los principales diccionarios de topónimos, vocabularios de flora y fauna y algunos estudios y glosarios de hablas jergales.

\section{Diccionarios generales de hondureñismos}

El primer diccionario, y hasta la fecha el más completo, es el de Alberto Membreño. Publicó en vida tres ediciones, siendo la tercera la más completa. Las dos primeras ediciones aparecieron en Tegucigalpa en 1895 y 1897 con el título de Hondureñismos. Vocabulario de los provincialismos de Honduras. La tercera y cuarta ediciones fueron publicadas en México en 1912 y 1921, respectivamente. La quinta edición no se publicó hasta 1982, en Tegucigalpa, por la Editorial Guaymuras ${ }^{25}$. En esta obra Membreño registra un gran número de hondureñismos y algunas expresiones y refranes. El propio autor nos aclara su concepto de hondureñismos:

Según el plan que nos propusimos al dar principio a este trabajo, él debería comprender: I. La etimología indígena de los nombres de lugares, montañas, ríos, etc., de la República (35). II. Los nombres, con su etimología, de las cosas indígenas de uso común. III. Las palabras que usamos en el trato diario y que, aunque son muy españolas, por ser anticuadas o por cualquiera otra causa, no figuran

${ }^{25}$ La ed. de Guaymuras es la $5^{\mathrm{a}}$ y no la $3^{\mathrm{a}}$ como señala la publicación. El texto de esta edición se tomó de la $2^{\mathrm{a}}$ y no de la $3^{\mathrm{a}}$ que es la definitiva de Membreño. Se le añadió como apéndice Hondureñismos de Jeremías Cisneros, publicado originalmente en 1907 en la Revista del Archivo y de la Biblioteca Nacional. 
en el Diccionario de la Academia. IV. Las voces españolas que hemos corrompido. $\mathrm{V}$. Los nombres de los vegetales y animales del territorio hondureño que no consten en las obras de botánica y zoología ${ }^{26}$.

Incluye como hondureñismos las palabras indígenas y aquéllas del español que han modificado parcialmente su significante, o han cambiado o añadido significados inexistentes en otras zonas dialectales del español. De los indigenismos, sólo señala la etimología de los nahuatlismos. Algunas entradas las documenta literariamente incluyendo citas textuales de obras literarias, científicas o de divulgación. El ilustre filólogo Ramón Menéndez Pidal, en una nota crítica a la primera edición de Hondureñismos, señalaba que Membreño incluye como hondureñismos muchos neologismos que se utilizan con igual significado en otras zonas de América y España. Entre otros, Menéndez Pidal señala contrabandear, editar, emocionarse, emperifollar, enraizar, etc. También afirma que son deficientes las explicaciones de algunas palabras como cancha, cigua, chulo y derrumbarse. Finalmente indica que no debe considerar como hondureñismos, por encontrarse registrados con igual o parecido significado por la Academia, las palabras alcancia , barbasco, cantina, embarrar, gallinero, gradilla, inscribir, lazar, liso, etc. ${ }^{27}$ En el prólogo a la segunda edición de su obra, Membreño escribe que "la juiciosa crítica del notable literato español señor Menéndez Pidal, ha sido atendida como lo merece para hacer algunas ligeras correcciones en el texto, ó para persistir en nuestra opinión'"28. Juan de Barcelona señala las palabras que Membreño, a pesar de las observaciones de Menéndez Pidal, continuó incluyendo como hondureñismos en la segunda edición. Estas palabras son: alcancia, cantina, embarrara, inscribir e indino ${ }^{29}$.

En 1907, Membreño publica en México un breve diccionario con el título Aztequismos de Honduras. En él registra doscientos veintiocho nahuatlismos, incorporándolos posteriormente a la tercera edición de Hondureñismos.

La publicación de Hondureñismos provocó una reacción en cadena. En casi todas las ciudades del país aparecen largas listas de

26 A. Membreño, Hondureñismos, III

27 MenÉndez PidAl, art. cit., p. 75.

28 A. Membreño, Hondureñismos, I.

29 Juan de Barcelona, "Notas críticas. El castellano de Venezuela de Julio Calcaño y Hondureñismos de Alberto Membreño'", Revista Crítica de Historia y Literatura Españolas, Portuguesas e Hispanoamericanas, 3 (1898), p. 7. 
palabras y expresiones no registradas en la obra de Membreño. La mayoría de palabras incluidas en estas listas son localismos o regionalismos y se citan más adelante. Todos los diccionarios y vocabularios del español de Honduras posteriores a la obra de Membreño tienen una indudable deuda.

$\mathrm{El}$ académico Carlos Izaguirre publica en el Boletín de la Academia Hondureña de la Lengua "Hondureñismos. Vocablos, giros y locuciones más corrientemente usadas en Honduras". Presenta un total de mil trescientas nueve entradas. Actualiza el diccionario de Membreño, pero tiene errores notables en algunas definiciones $^{30}$.

En 1964, Rosalío Zabala publica en Bogotá, como apéndice del Diccionario escolar de la lengua española, unos tres mil hondureñismos. Es notoria su deuda con las obras de Membreño e Izaguirre.

Thomas H. Walz (1964) publica un diccionario titulado Favorite idioms and expressions used in Honduras. La obra, como él mismo señala, va dirigida a "empleados del Gobierno de habla inglesa, estudiantes, misioneros y voluntarios del Cuerpo de Paz". La divide en cinco apartados: lista de las palabras más usadas en Honduras; categorías idiomáticas; palabras de uso común que son tabú; recibimientos cortos, saludos y observaciones y los gestos de cuerpo y manos más utilizados.

\section{Vocabularios regionales y locales}

Son abundantes pero difíciles de consultar por haberse publicado en efímeras revistas y periódicos locales. La publicación de Hondureñismos de Membreño tuvo un efecto multiplicador, ya que propició la publicación de vocabularios que incluían términos no registrados por este autor, o documentaban más ampliamente los existentes. Jeremías Cisneros en la introducción a sus Hondureñismos señala las razones para publicar su lista de hondureñismos, a pesar de ser colaborador de A. Membreño:

Empero, una vez publicada la obra $\left[2^{\mathrm{a}}\right.$ ed. de Hondureñismos de Membreño], he llegado á notar: $1^{\circ}$ que palabras o frases ... tienen aquí [departamento de Gracias] otra estructura ortográfica; $2^{\circ}$ que mu-

30 Cf. Atanasio Herranz, "Alberto Membreño y la lexicografía en Honduras', Español. Antología, Guaymuras, Tegucigalpa, 1983, p. 83. 
chas de esas palabras tienen aquí una acepción, sino contraria al menos diversa; $3^{\circ}$ que la mayoría de palabras contenidas en Hondureñismos, además del significado que ahí se les da, tienen aquí otro adicional; y $4^{\circ}$ que por acá hay voces que no figuran en Hondurenismos ${ }^{31}$.

El vocabulario de Jeremías Cisneros (1907) tiene doscientas siete entradas. La mayoría son palabras y expresiones usadas en la ciudad de Gracias y, en general, en el occidente del país.

En 1906 aparecen los "Provincialismos y barbarismos de Honduras"' de Eduardo Martínez López. Incluye ciento cincuenta y cuatro voces, colocando al lado derecho la palabra correcta del español estándar. Comete algunos errores en los términos estándar seleccionados. Como ya se señaló, aporta datos interesantes para el estudio fonético del habla hondureña.

En 1914, Francisco José Elvir publica, en el periódico El Nuevo Tiempo, "Más hondureñismos". Contiene unas doscientas veintitrés voces y expresiones. Registra algunas palabras que aparecen en el diccionario de Membreño para reforzar su significado y la documentación de su uso a través de expresiones populares y citas de obras literarias hondureñas.

De 1951 a 1956, la Academia Hondureña de la Lengua, a instancias de la Comisión de Lexicografía de su homóloga española, solicitó a personalidades e instituciones educativas la recopilación de palabras y giros de uso local o regional. Entre 1955 y 1956 se publicaron numerosas listas de localismos y regionalismos en el Boletín de la Academia Hondureña de la Lengua. Todos estos vocabularios definen, generalmente por el sistema de sinónimos, las palabras registradas. La mayoría de vocabularios fueron recogidos por alumnos de educación primaria, media y magisterio. Destacan los publicados en el citado Boletín: Fernando Figueroa "Algunas palabras de uso común usadas (sic) por el pueblo de Olancho"; Francisco López: "Hondureñismos usados en el departamento de Lempira'"; Instituto Francisco J. Mejía: "Hondureñismos recogidos en Olanchito, departamento de Yoro" ; Instituto Departamental de Occidente: "Hondureñismos recogidos en La Esperanza, departamento de Intibucá"; Instituto Ramón Rosa: "Hondureñismos recogidos en Gracias, departamento de Lempira”; Instituto La Fraternidad: "Hondureñismos recogidos en Jutical-

${ }^{11}$ Cisneros, "Hondureñismos", en A. Membreño, Hondureñismos, $5^{\mathrm{a}}$ ed., Guaymuras, Tegucigalpa, 1982, p. 212. 
pa, departamento de Olancho", Sor María Teresa Castro: “'Hondureñismos de Santa Rosa de Copán' ; Escuela Normal de Villa Ahumada: "Hondureñismos recogidos en Danlí, departamento del Paraíso"'; Escuela de Curarén: "Hondureñismos recogidos en Curarén, departamento de Francisco Morazán' ; Escuela de Trujillo: "Hondureñismos del departamento de Colón", e Instituto La Independencia: "Algunos vocablos y modismos usados en el departamento de Santa Bárbara'.

Como regionalismos de la costa norte de Honduras pueden considerarse un buen número de los ciento treinta términos que se incluyen en el glosario de la novela bananera Prisión Verde de Ramón Amaya Amador ${ }^{32}$. Estas palabras las utilizan los trabajadores de las compañías bananeras. Estos trabajadores, llamados 'campeños', en su mayoría son emigrantes de pueblos del interior de Honduras, sobre todo de los departamentos de Olancho y Yoro. La emigración comenzó a partir de 1906 con la instalación en la costa Atlántica de Honduras de varias compañías bananeras. Inexplicablemente este glosario se ha omitido a partir de la tercera edición.

Todos estos vocabularios están cargados de indigenismos, arcaísmos, barbarismos y transposiciones semánticas. Han sido recopilados por personas con escasa formación lingüística y, por lo general, definen las entradas por el sistema de sinónimos. Algunos vocabularios, como los de Olancho y Colón, incluyen indigenismos y palabras del garífuna, lengua caribe. Un análisis lingüístico de estos vocabularios ayudaría en la elaboración de cuestionarios léxicos para la delimitación de las zonas dialectales del español de Honduras.

\section{Diccionarios de topónimos}

Corresponde nuevamente a Membreño el honor de haber publicado en 1901 la obra más completa de toponimia hondureña: Nombres geográficos indígenas de la República de Honduras. En el prólogo estudia varios sufijos como -gua, -gual, -guara, -ili, -ire, -laca, -li, -terique, etc. Presenta ciento quince topónimos náhuatl de Guatemala y ciento ocho de Nicaragua con el objeto de demostrar la gran influencia de esta lengua en toda Centroamérica y, por tanto, en Honduras. En la parte central de la obra incluye casi ocho- 
cientos ochenta topónimos hondureños, señalando la etimología de la mayoría. La creencia de Membreño, no sin fundamento, que la mayoría de topónimos proceden del náhuatl le llevó a forzar etimologías y olvidar que otras lenguas de Honduras como el lenca, maya-chortí, chorotega, etc., también dejaron sus huellas en la toponimia hondureña ${ }^{33}$. Entre 1967 y 1970 la revista Anales del Archivo Nacional publica los Nombres indigenas de Honduras de los departamentos de Olancho, Santa Bárbara, Francisco Morazán y Copán. Estas listas son nombres de pueblos y aldeas extraídos de la obra de Membreño.

En 1952 aparece el Diccionario histórico-geográfico de las poblaciones de Honduras de M. Bonilla. Contiene doscientos ochenta y siete nombres de caseríos, aldeas, pueblos y ciudades de Honduras. Etimológicamente no aporta nada nuevo a la obra de Membreño.

J. Aguilar Paz publica en 1969 un extenso artículo titulado "Toponimias y regionalismos de Honduras". La estructura de este artículo es muy extraña. Presenta una pequeña introducción donde señala al habla de Castilla como base del español de Honduras complementándose con la aportación léxica de las lenguas indígenas de Mesoamérica. Después enumera, por series de dos o tres palabras, topónimos y algunos nombres de plantas y alimentos. En cada serie muestra la etimología del prefijo común. Por ejemplo: Yusguarán, Yusguare y Yusmerán tienen como prefijo común yus- 'grande'. A continuación, en versos eneasílabos de estrofas y rimas irregulares, agrupa algunos campos léxicos. En la última parte ordena una serie de términos, que en su mayoría no son topónimos, clasificándolos según la lengua de substrato o adstrato de procedencia. En total setenta y ocho voces taínas y caribes, ciento setenta y ocho mexicanas y tres miskitas.

H. Kessler Meyer publica en $1976 \mathrm{el} \mathrm{Historical} \mathrm{dictionary} \mathrm{of} \mathrm{Hon-}$ duras. Incluye mil quinientos nombres de lugares, personajes y hechos importantes de la historia de Honduras. Sus aportaciones lingüísticas son irrelevantes.

Francisco Flores presentó en la XIV Mesa Redonda de la Sociedad Mexicana de Antropología la ponencia “Topónimos indígenas de los departamentos de Gracias a Dios, Olancho, El Paraíso y Choluteca'. En ella incluye treinta y tres voces, señalando su etimología. La mayoría de ellas son de las lenguas miskita y sumo. El resto del idioma paya.

Anne Chapman presenta en su obra, Los lencas de Honduras en

33 Véase A. Herranz, art. cit. 
el siglo $X V P^{34}$, una lista de cuatrocientos nueve nombres de pueblos $y$ aldeas de origen lenca, indicando el año en que por vez primera aparece citado en un documento colonial. Previamente señala nueve prefijos y sufijos lencas, indicando su etimología, que aparecen en la mayoría de topónimos lencas registrados. A. Chapman toma los prefijos y una gran mayoría de los topónimos lencas de Walter Lehmann ${ }^{35}$.

\section{Vocabularios de flora y fauna}

Son relativamente abundantes este tipo de vocabularios. Casi todos incluyen los nombres comunes de cada animal o planta y su nombre científico. En contadas ocasiones indican la etimología del nombre común.

A. Alfaro Arriaga, Luis Landa y Tobías Rosa han trabajado en la catalogación y descripción de aves de Honduras. Sobre flora hondureña destaca la acuciosa labor de Ciryl H. Nelson con su excelente obra Las plantas comunes en Honduras. Otros autores que han trabajado sobre flora hondureña son Tobías Rosa y M. Cruz Zambrano. Sobre mamíferos merece citarse el trabajo de Ear H. Klein (1977) y, sobre todo, Mamíferos de mi tierra de I. Gamero Idiaquez. Además en 1963 había publicado con criterios pedagógicos el trabajo Las voces de los animales. En él recoge sesenta y ocho verbos que denotan el canto y sonido característico de muchos animales de Honduras. Gustavo A. Cruz recoge en su estudio Serpientes venenosas de Honduras el nombre común de las más comunes y peligrosas de ellas. Especial mención merece la obra La botica del pueblo de Francisco Cruz. En ella se registran un buen número de nombres de plantas, raíces, animales y productos caseros que se utilizan para curar enfermedades. A. Membreño ${ }^{36}$ la consultó para la elaboración de su diccionario.

Vocabularios y estudios de hablas jergales

La mayor parte de estos trabajos son lexicográficos y todos ellos han recopilado listas de palabras del habla de ladrones y rateros.

${ }^{34}$ Instituto Hondureño de Antropología e Historia, Tegucigalpa, 1978, pp. 38-53.

35 W. Lehman, Zentral-Amerika, Berlin, 1920, t. 2, pp. 624-625, 671-682.

${ }^{36}$ Membreño, Hondureñismos, V. 
La mayoría de los autores ha recogido sus datos en la Penitenciaría Central de Tegucigalpa. La obra de Martín Alvarado, Caló hondureño, ha sido la más consultada. Muestran un buen número de palabras y expresiones los trabajos de Manuel Valladares y Luis Hernán Sevilla en su tesis El lenguaje del hampa en Honduras. La obra más estructurada y con mayor rigurosidad y análisis del habla jergal es Léxico del delincuente hondureño de Elba Nieto.

Necesidad de estudios más sistemáticos

y globales del español de Honduras

A pesar de la abundancia de vocabularios reseñados y de algunos estudios sobre el español de Honduras, se necesita con urgencia un estudio global que abarque los planos fonético-fonológico, morfosintáctico y léxico-semántico realizado en todo el territorio nacional por un equipo de especialistas. Este estudio-diagnóstico permitiría conocer las principales características del habla hondureña y se iniciaría la delimitación de sus zonas dialectales. La necesidad de este estudio global se basa en los siguientes razonamientos:

a) Los estudios publicados en la actualidad cubren únicamente aspectos parciales del habla hondureña.

b) La mayoría de los estudios publicados hasta 1983 han sido realizados por personas no especializadas, observándose en muchos trabajos notorias deficiencias tanto en la recolección de datos como en su análisis.

e) El simple recuento de la bibliografía hondureña muestra por un lado el dominio abrumador de trabajos lexicográficos y por otra, la práctica inexistencia hasta 1983 de trabajos fonéticos-fonológicos.

d) Los trabajos lexicográficos del español de Honduras, a excepción de los de Alberto Membreño y, tal vez, el de Carlos Izaguirre, registran un buen número de palabras de escasa vigencia en el habla hondureña, aun en el momento en que fueron recopiladas. Abundan en estos diccionarios y vocabularios los localismos, barbarismos, arcaísmos e indigenismos, que reflejan, casi exclusivamente, el habla rural.

e) Es apremiante conocer el español hablado en las ciudades de San Pedro Sula y Tegucigalpa, que son focos lingüísticos irradiadores y donde vive la mitad de la población de 
Honduras. Además es necesario conocer las variantes diatópicas y diastráticas e iniciar los estudios diacrónicos del español de Honduras.

No obstante lo anterior, ya hay algunas realizaciones y se vislumbran alentadoras perspectivas de nuevos estudios sobre el español de Honduras. El pasado mes de diciembre colaboré con el profesor Antonio Quilis en la selección de lugares e informantes para la aplicación del Cuestionario del Atlas Lingüistico de Hispanoamérica. Se espera que para 1992 esté concluida esta magna obra que dirige Manuel Alvar. Por otra parte, la especialidad de Lingüística de la carrera de Letras de la Universidad de Honduras, tímidamente quiere iniciar los trabajos de investigación del español de Honduras. Parece, pues, que en la próxima década el español de Honduras podría dejar de ser la cenicienta de los dialectos del español de América.

Atanasio Herranz $\mathrm{H}$.

Universidad Nacional Autónoma de Honduras 


\section{APÉNDICE}

Bibliografía del español de Honduras

Agullar Paz, Jesús

1933 Mapa de Honduras, Tegucigalpa.

1928 "Significado de la palabra Tegucigalpa", Revista del Archivo y de la Biblioteca Nacional, 6 (8), 273-274. Nuevamente publicado en Revista del Archivo y de la Biblioteca Nacional, 22 (6), 373-374.

1968 * Toponimias y regionalismos indígenas de Honduras, Instituto Geográfico Nacional de Honduras, Tegucigalpa, $35 \mathrm{pp}$.

Posteriormente ha sido reproducido con el mismo título en 1969 en $B A H o, 13$ (13), 127-161 y en 1978 en la revista Presente, 2 (16), 3-18 y $2(18), 3-11$.

(Este artículo tiene una extraña estructura: señala el origen castellano del español de Honduras y la importancia de las lenguas mesoamericanas; después agrupa, por pares o tríos, topónimos, nombres de plantas o alimentos, indicando la etimología del prefijo o raíz de cada grupo; continúa enumerando hondureñismos en versos eneasílabos de estrofas irregulares; culmina el trabajo definiendo y clasificando doscientos cincuenta y nueve términos según la lengua de substrato o adstrato de procedencia; setenta y ocho voces taínas y caribes, ciento setenta y ocho mexicanas o náhuas y tres miskitas.)

1981 El refranero hondureño, Guaymuras, Tegucigalpa, 78 pp.

(Incluye mil doscientos dos refranes y expresiones del habla hondureña. También muestra algunas estrofas populares llamadas "bombas".)

Aguilar Pinel, Carlos

1940 Lecciones de analogía, ortografía y lecturas razonadas. Primer curso, Imp. Calderón, Tegucigalpa, $132 \mathrm{pp}$.

(Es un libro de texto del ciclo común. Incluye una lista de cuarenta palabras extranjeras usadas en Honduras, la mayoría son anglicismos y galicismos. También incorpora algunos neologismos del latín.) 
1976 "El hai kai en los predios ornitológicos de Honduras", BAHo, 19 (19), 129-131.

(Describe veintiún aves de Honduras, señalando sus nombres comunes y el científico.)

Alvarado, Florencio

1952 Folklore nacional: caló hondureño (vulgarismos), Imp. La Democracia, Tegucigalpa, $30 \mathrm{pp}$.

(Contiene una lista de palabras y frases. Lo incluyó H. C. WordBRIDGE en su "Central American Spanish. A bibliography, 1940-1953'.)

Alvarado Rodríguez, Martín

1963 Doctor'Antonio R. Vallejo (biografía), Imp. La República, Tegucigalpa, $28 \mathrm{pp}$

(Contiene algunos datos sobre la labor lingüística de Vallejo.)

1973 Cantarranas, $2^{\mathrm{a}}$ ed., Imp. López, Tegucigalpa, $215 \mathrm{pp}$.

(Es un libro de relatos de tradiciones, costumbres y personajes del pueblo de Cantarranas, próximo a Tegucigalpa. En los relatos [pp. 25113] utiliza un regular número de voces y expresiones populares.)

Álvaro lozano, Andrés

1978 “Día del idioma de Cervantes", La Prensa, San Pedro Sula, 6 de mayo, p. 6.

Amaya Amador, Ramón

1950 Prisión verde, Latina, México, 244 pp.

1957 Prisión verde, AGEPE, Buenos Aires.

(Incluye un apéndice con ciento noventa y cuatro palabras y expresiones que aparecen en la novela y de uso común entre los trabajadores de las compañias bananeras de la costa norte de Honduras. Muchas de las palabras y expresiones se usan en toda la República, otras son anglicismos y el resto tecnicismos o voces jergales.)

Andrade, Noemí, Gisele Zelaya y Marta Cabrera

1983 Grado de interferencia a nivel morfosintáctico en el español utilizado en la tribu de El Palmar. Yoro, tesis de Bachillerato Universitario en Letras, Universidad Nacional Autónoma de Honduras, 129 pp.

(Muestra la interferencia de la lengua tol o jicaque en el español hablado en la comunidad. La lengua tol se hablaba en esa comunidad como lengua materna hasta hace dos generaciones. Las interferencias se dan sobre todo en el género y número de sustantivos, adjetivos, artículos y pronombres. Se hallaron problemas de concordancia entre el verbo y el sujeto y entre el modificador y modificadores. Incluve, como apéndice, un vocabulario tol usado por algunos miembros de mayor edad de la comunidad.)

Antúnez Castillo, RubÉn

1941 Lecciones de sintaxis y composición, $3^{\mathrm{a}}$ ed., José Trinidad Reyes, San Pedro Sula, 190 pp. 
1955 "Hondureñismos de uso frecuente consultados en el diccionario titulado El pequeño Larousse", Revista de Educación Primaria, 3 (31), 48-49. cados.)

(Incluye ciento treinta hondureñismos con sus respectivos signifi-

1956 "Hondureñismos que aparecen en el Diccionario de la Real Academia Española, Xvil edición de 1947", BAHo, 2 (2), 63-82.

(Registra ciento noventa y cuatro entradas con sus respectivos significados, copiados textualmente. En algunas definiciones añade observaciones $o$ incluye nuevas acepciones que se dan en Honduras y que no las registra el $D R A E$.)

ARdón, JuAn Ramón

1965 Enciclopedia de las siglas, Maqui-Grafic, Comayagüela, Honduras, 396 pp.

(Divide su obra en los siguientes apartados: guía analítica de siglas hondureñas, explicación histórica de ellas, guía de siglas internacionales y abreviaturas y expresiones latinas más usuales.)

ARDÓN, Víctor F.

1954 "El idioma nacional, símbolo de la patria", Revista de Educación Primaria, 2 (20), 13-21.

(Divide el artículo en varias partes. En la primera trata de fundamentar la campaña de "conservación y pureza de la Lengua Castellana", iniciada por el Ministerio de Educación. Seguidamente presenta un bosquejo del Plan de Acción donde se proponen medidas como evitar carteles en lenguas extranjeras, publicar cartillas bilingües para Islas de la Bahía y La Mosquitia, etc. La tercera parte da indicaciones concretas a los maestros para mantener la pureza del idioma. La cuarta parte contiene "formas incorrectas de expresión que deben sustituirse por las formas correctas que aquí mismo se indican". La quinta muestra expresiones y palabras mal usadas en Honduras, pluralización indebida del verbo haber, concordancia de sujeto y verbo en oraciones de pasiva con se y verbos irregulares.)

1956 "Ortografía castellana", BAHo, 3 (4), 7-15.

1959 Nociones de filología, $4^{\text {a }}$ ed., Imp. La República, Tegucigalpa, 124 pp.

(No incluye observaciones sobre el español de Honduras.)

1974 Castellano. Primer curso. Ciclo común de cultura, $6^{\mathrm{a}}$ ed., Imp. Tulín, Tegucigalpa, 205 pp.

(En el capítulo 3 incluye varios sinónimos de niño, judías y cerdo utilizados en Honduras. En el capítulo 9 muestra setenta y cuatro refranes y diecinueve adivinanzas.)

Ardón Mejía, Mario

1986 Folklore lúdico infantil hondureño, Asociación Save the Children, Tegucigalpa, 152 pp.

(Recoge un buen número de rondas y cantos, juegos y nombres de juguetes comunes en Honduras.) 
(En palabras del autor "contiene, entre otros asuntos, el estudio de numerosos vocablos y locuciones que con frecuencia suelen emplearse en forma impropia e incorrecta". Tiene un total de doscientas cincuenta y siete entradas. Muchas de las voces registradas son palabras que se pronuncian en Honduras con alguna variación fonética, como por ejemplo blanquimento por blanqueamiento. Otras son confusiones semánticas y, un menor número, errores morfológicos.)

Barcelona, JUAN DE

1898 "Notas críticas. El castellano de Venezuela de Julio Calcaño y Hondureñismos de Alberto Membreño", Revista Crítica de Historia y Literatura Espanolas, Portuguesas e Hispanoamericanas, 3 (1), 1-9.

1898 “Hondureñismos. Nota crítica”, Semanario Ministerial "La Unión", Tegucigalpa, (83), 23 de abril, p. 1.

(En el Semanario Ministerial se reproduce sólo lo referente a Hondureñismos de Membreño publicado en Revista Crítica de Historia y Literatura Españolas, Portuguesas e Hispanoamericanas, J. Barcelona reconoce en su nota que A. Membreño, en esta segunda edición, ha incorporado un gran número de palabras nuevas. Critica el empecinamiento de Membreño al continuar incluyendo como hondureñismos palabras como alcancía, cantina, embarrar, inscribir e indino, a pesar que Menéndez Pidal le había señalado, en una nota crítica a la primera edición, que esas palabras eran de uso común en España.)

Barrera Valenzuela, Pedro

1950 "Etimología de la palabra Tegucigalpa", Revista del Archivo y de la Biblioteca Nacional, 28 (9-10), 438.

Bonilla, Marcelina

1952 Diccionario histórico-geográfico de las poblaciones de Honduras, $2^{\text {a }}$ ed., Imp. Calderón, Tegucigalpa, $310 \mathrm{pp}$.

(Contiene unos seis mil nombres de pueblos, aldeas y caseríos. Etimológicamente sigue a A. Membreño en su obra Nombres geográficos indigenas de la República de Honduras.)

BotTo Handal, Gabriela

1968 Algunas peculiaridades del idioma español en Honduras, tesis de Profesorado en Educación Media en Letras, Escuela Superior del Profesorado "Francisco Morazán”, 58 pp.

(En el capítulo 2 señala como caracteres principales del español de Honduras en el plano morfológico y sintáctico los siguientes: vacilaciones en el género de algunos sustantivos, uso del voseo, confusión en el uso de algunas preposiciones y cambios en el orden oracional. En el capítulo 3 señala los sufijos más usuales en el habla hondureña y caracteriza el habla rural por el uso frecuente de indigenismos, arcaísmos y modismos. El habla de la ciudad la caracteriza por el uso de préstamos del inglés y el francés y por la existencia de hablas jergales de grupos como estudiantes y jugadores de billar y naipes. Termina la obra con una recopilación de refranes usados en Honduras. Al trabajo le falta 
análisis y una metodología más sistemática. No señala el origen concreto de los datos recopilados.)

Canfield, D. Lincoln

1960 “Observaciones sobre el español salvadoreño", Fil, 6, 29-76.

(El autor señala marginalmente algunos aspectos del español de Honduras, basándose en unas grabaciones que hizo en Tegucigalpa en el verano de 1952. Entre los aspectos que señala destaca la unidad fonética y léxica del español de El Salvador, Honduras y Nicaragua y la similitud en la pronunciación de algunos sonidos como el diptongo leu/ y la $/ s /$ en determinados contextos.)

1981 * Spanish pronunciation in the Americas, University of Chicago, Chicago, pp. $1-17$ y $58-59$

(En esta obra sistematiza la tendencia del habla hondureña en la pronunciación de los fonemas $/ \mathrm{b}, \mathrm{d}, \mathrm{g} / \rightarrow[\mathrm{b}, \mathrm{d}, \mathrm{g}]$ (después de otra consonante o semivocal); $/ \mathrm{s} / \rightarrow[\mathrm{s}]$ o $[\theta] ;-/ \mathrm{n} / \rightarrow[\eta]$ (en final de palabra antes de pausa o vocal $) ; / \mathrm{x} / \rightarrow[\mathrm{h}] ; / 1 / \mathrm{e} / \mathrm{y} / \leftrightarrow[\mathrm{y}]$ o $[\mathrm{i}] ; / \overline{\mathrm{r}} / \rightarrow[\overline{\mathrm{r}}]$. Co-

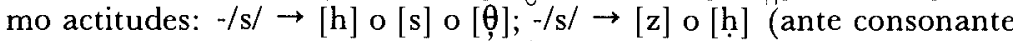
vocalizada); $/ \mathrm{f} / \rightarrow[\mathbf{p}]$ o[f]; $/ / \mathrm{d} / \rightarrow[\phi]$ o $[\theta]$. Reconoce tener pocos datos del habla de las ciudades de Ceiba y San Pedro Sula situadas en la costa atlántica de Honduras).

Cantor, Argentina viuda de

1956 "Lista de palabras y locuciones extranjeras de uso corriente en el castellano: galicismos, anglicismos y latinismos", Revista de Educación Primaria, 5 (52-53), p. 48.

(Presenta una breve historia de los préstamos del francés al castellano y veinticuatro anglicismos usados en Honduras.)

Cárcamo Tercero, Hernán

1978 "Algo", BAHo, 21 (21), 101-102.

1978 "Nuestro idioma", BAHo, 21 (21), 99-100.

(Son dos breves artículos que señalan generalidades del español.)

Carías Chaverri, Claudia M., Héctor M. Leyva et al.

1985 Literatura oral en la comunidad de Yamaranguila, departamento de Intibucá, tesis de Bachillerato en Literatura, Universidad Nacional Autónoma de Honduras, $215 \mathrm{pp}$.

1988 Tradición oral indígena de Yamaranguila, Guaymuras, Tegucigalpa, 207 pp.

(Tradición oral indígena de Yamaranguila es una adaptación de la tesis Literatura oral. . . Lingüísticamente interesa la transcripción gráfica de un buen número de relatos y mitos grabados en esa comunidad. Incluye en algunas citas el significado de algunas palabras y expresiones de los relatos.)

Castro, Sor María Teresa

1956 "Hondureñismos. Santa Rosa de Copán”, BAHo, 2 (2), 115-119.

(Tiene noventa entradas con sus respectivos significados.) 
Cisneros, Jeremías

1906 "Lempira", Revista del Archivo y de la Biblioteca Nacional, 3 (1), 12-13.

(Es un poema al héroe Lempira. En la nota segunda señala el significado de algunos prefijos y sufijos que el autor considera lencas: gual-, -ique, -ite, -gual, -aca, -peque y -engo.)

1907 "Hondureñismos", Revista del Archivo y de la Biblioteca Nacional, 3 (5), $154-157 ; 3$ (6), 181-183; 3 (7), 313-314; 3 (8), 350-353; 3 (9), 282-285 y 3 (10), 313-316. Se publicó nuevamente como apéndice del diccionario de Hondureñismos de A. Membreño, Guaymuras, Tegucigalpa, 1982, pp. 211-232.

(Presenta doscientas siete entradas con sus significados y, al final de la obra, algunas consideraciones generales sobre el leismo y loismo. J. Cisneros fue un colaborador de A. Membreño y publicó este vocabulario como complemento a la segunda edición de Hondureñismos. Muchos de los términos que incluye Cisneros son localismos o regionalismos de la ciudad de Gracias y del occidente del país.)

Claros, Eufemiano

1961 "Lingüística hondureña. Notas en el departamento de Gracias a Dios, República de Honduras", BAHo, 6 (7), 79-84.

(Es un artículo extraño. Al inicio explica la penetración azteca en la costa atlántica de Honduras y presenta una lista de veinte nombres del náhuatl tomados del Libro de los días o Tonalamatl, comparándolos con nombres del Pepil y Niquiramo. Finaliza el artículo con una lista de veinte voces que el miskito ha tomado del inglés.)

Cortés, Carlos R.

1954 "Programa de castellano de primer grado. Ortología. Pronunciación correcta de las palabras y sonidos", Revista de Educación Primaria, 3 (30), 2-5.

(Presenta inicialmente una lista de palabras mal pronunciadas en las zonas rurales y al lado la pronunciación correcta. Los fenómenos fonéticos son: - /d/ implosiva final no se pronuncia, lo mismo que la [x]; se cambian algunos sonidos como $/ \mathrm{d} />[\mathrm{g}], / \mathrm{l} / \mathrm{implosiva}$ por $/ \mathrm{r} / \mathrm{y}$ viceversa, $/ \mathrm{x} /$ por $/ \mathrm{f} /$ y viceversa; $/ \mathrm{h} /$ - inicial $>[\mathrm{g}]$; metátesis y epéntesis de la /y/ en las terminaciones -ía [maríya]. Posteriormente muestra las onomatopeyas usuales al llamar o imitar el canto de quince animales.)

1956 "Hondureñismos", Revista de Educación Primaria, 4 (45), 46-47.

(Presenta una lista de cien hondureñismos con sus respectivos significados.)

Costales Samaniego, Alfredo

S.f. Diccionario de modismos y regionalismos centroamericanos (Costa Rica, Nicaragua, Honduras, El Salvador y Guatemala), CSUCA, San José de Costa Rica, $83 \mathrm{pp}$.

(En el primer capítulo registra cincuenta y siete entradas, correspondientes a las labores agrícolas de Centroamérica y veintitrés nombres de instrumentos de labranza. Porteriormente, señala los sistemas de pesas y medidas usados en el área centroamericana, registrando die- 
ciocho voces. Termina con un vocabulario general del área con sesenta y ocho entradas. Siempre señala el significado de cada palabra y los países donde se usa. A veces señala la etimología de las palabras, en especial las de procedencia quéchua.)

Cruz, Francisco

1901 Flora medicinal de Honduras. Botica del pueblo, $3^{\text {a }}$ ed., Enrique Rojas, Madrid, $347 \mathrm{pp}$.

(En el primer capítulo incluye los nombres de plantas, animales, raíces y sustancias que curan enfermedades. El segundo capítulo recoge un formulario de recetas domésticas. El tercero recoge alfabéticamente nombres de enfermedades y aforismos. La cuarta y última presenta una lista de enfermedades y su forma de curación.)

Cruz, Ramón E.

1964 "El doctor don Alberto Membreño", BAHo, 9 (10), 5-12.

Cruz, Gustavo Adolfo

1987 Serpientes venenosas de Honduras, Universidad Nacional Autónoma de Honduras, Tegucigalpa, 160 pp. (Docencia 46).

(Interesa para la lingüística los distintos nombres comunes que registra de serpientes venenosas de Honduras como barba amarilla, tamagás, timbo y coral.)

Cruz Zambrano, Miguel A.

1985 Notas etimológicas botánicas, Universidad Nacional Autónoma de Honduras, Tegucigalpa, $47 \mathrm{pp}$.

(Divide el trabajo en cuatro apartados. En el primero incluye trescientos sesenta nombres árabes de plantas que han pasado al castellano. En el segundo cincuenta y dos nombres de plantas del gallego y portugués que vienen del árabe. El tercero muestra cincuenta y ocho nombres de plantas de cultivo común y la última parte ciento noventa y seis nombres vulgares de plantas que aparecen en documentos y libros desde la época colonial hasta 1871.)

Chapman, Ana

1978 Los lencas de Honduras en el siglo XVI, Instituto Hondureño de Antropología e Historia, Tegucigalpa, pp. 38-53.

(La última parte incluye el significado de algunos sufijos lencas como güirán 'pueblo', teríque 'cerro', quin 'camino', guara 'río', guala 'mano', guas 'agua', tega o teca 'llanura', cogtón 'montaña', t'au o taug 'casa' y lepa 'jaguar'. En seguida presenta una lista de cuatrocientos nueve topónimos de pueblos y aldeas que aparecen en distintos documentos coloniales.)

Durón, Rómulo E.

1921 "Discurso... en la inhumación de los restos del Dr. don Alberto Membreño", Revista de la Universidad, 11 (2), 97-99. 
Elvir, Francisco José

1914 "Más hondureñismos", El Nuevo Tiempo, 14 al 29 de julio. Nuevamente se publicó en 1972 en $A A N, 6$ (11), 51-69.

(El autor nos señala en la introducción que la lectura de la tercera edición de Hondureñismos de Membreño le motivó para ampliar su número, documentar algunos y señalar el carácter connotativo de otros. Tiene un total de doscientas veintitrés entradas. Es rico en expresiones populares y refleja algunas particularidades fonéticas del español de Honduras.)

ENAMORADO, J. B.

1957 "Siglas usuales", Revista de Educación Primaria, 5 (55-56), p. 56.

(Define el concepto de sigla y presenta veintinueve siglas comunes en Honduras.)

Escuela Normal Rural de Señoritas de Villa Ahumada

1956 "Hondureñismos: Danlí, departamento de El Paraíso", BAHo, 2 (2), 144-146.

(Incluye cuarenta y nueve palabras y trece refranes y expresiones usadas en ese departamento.)

Escuela Urbana de Trujillo

1956 "Hondureñismos: Trujillo, departamento de Colón", BAHo, 2 (2), 120-122.

(Consta de cuarenta y dos entradas con su significado. Algunas palabras son de la lengua caribe o garífuna.)

Escuela Urbana Mixta de Curarén

1956 "Hondureñismos: Curarén, departamento de Francisco Morazán", BAHo, 2 (2), 142-143.

(Tiene veintiocho entradas con sus respectivos significados. Algunos son localismos.)

Figueroa, Fernando

1955 "Hondureñismos: algunas palabras de uso común usadas [en] el pueblo de Olancho", BAHo, 1 (1), 131-138.

(Muestra un total de doscientas setenta entradas. Incluye en ellas algunos topónimos. Olancho es el departamento más extenso de Honduras, J. M. LOPE BLANCH cita, en El español de América, este vocabulario de F. Figueroa que por error tipográfico aparece como Fuguerva, p. 91.)

Flores Andino, Francisco A.

1976 "Toponimias indígenas de los departamentos de Gracias a Dios, Olancho, El Paraíso y Choluteca", en Las fronteras de Mesoamérica, Sociedad Mexicana de Antropología, México, t. 2, pp. 367-374.

(Incluye treinta topónimos y señala su etimología. Considera a la mayoría como provenientes de las lenguas suma y miskita.) 
Flores, ÓsCar A.

1956 "Hondureñismos", BAHo, 2 (2), 110-114.

(Señala el significado de sesenta y siete hondureñismos generales.)

Gálvez, Carlos M.

1964 "La lengua castellana", $B A H o, 9(10), 1-3$.

1971 "Don Andrés Bello", BAHo, 14 (14), 1-6.

1975 "La lengua española como problema", $B A H o, 18$ (18), 1-11.

(Este artículo incluye cuestiones generales de los orígenes y evolución del castellano. La parte medular la dedica a informar sobre su labor en la Academia Española de la Lengua como miembro de la Comisión de Directorios, en representación de la Academia Hondureña de la Lengua. Presentó para que fueran aprobados - aunque no lo fueronpor la Comisión Permanente los siguientes hondureñismos: tuco, tuquito, La Sucia, chiquioso, careto, nainitas, chingaste, chojin, amapuches, cadejo, bambador, nixtamal, guaro, chigüin, cachinflín, bamba y paninato. Fueron aceptados y ratificados por el plenario de la Real Academia para ser incluidos como hondureñismos en la vigésima edición del Diccionario de la Corporación los siguientes: achaparrado, cumbo, cumbearse, palomilla, nique, percocho, bamba, mecapal, mecapalero, sardo y sardito.)

Gamero Idiaquez, Ibrahim

1963 Las voces de los animales, Navarro, Comayagüela, $61 \mathrm{pp}$.

(Contiene la definición de sesenta y ocho verbos que denotan el canto y sonidos característicos de cada animal. Después identifica y describe los animales y aves que utilizan cada una de esas voces.)

1978 "Mamíferos de mi tierra", BAHo, 21 (21), 15-55.

(Señala los nombres comunes y el científico de ochenta y cinco animales de Honduras. Describe su hábitat, comportamiento, aspecto físico, etc.).

1978 Mamifferos de mi tierra, 2 ts., Imp. López, Tegucigalpa, 427 pp.

(Estudia un gran número de animales mamíferos de Honduras. Senala en cada animal su familia, nombre científico, nombres comunes, descripción y hábitat. Indica la etimología de los nombres de lenguas indígenas y en ocasiones muestra los sinónimos en náhuatl, maya, tupíguaraní, etc.).

González, Miriam A. y Normanda L. Martínez

S.f. "Uso regional del verbo en Honduras", tesis de Profesora en Educación Media en Letras, Escuela Superior del Profesorado "Francisco Morazán", $40 \mathrm{pp}$.

(Esta tesis, en su parte central, muestra el cambio de significado en el habla hondureña de doce verbos y la ampliación de significado de cinco. En el capítulo 4, incluye algunos ejemplos del mal uso de modos, tiempos, números y personas, verbos regulares e irregulares, transitivos e intransitivos y algunos cambios fonéticos. En el capítulo 5 presenta una lista de sesenta y nueve verbos usados en el español de Honduras que no aparecen en el $D R A E$, y una lista de quince verbos que sufren modificaciones fonéticas en su pronunciación. Los ejemplos que 
aparecen en la tesis pueden ser del habla de Tegucigalpa, aunque no se dice expresamente. No aparecen los listados de los informantes. Algunos ejemplos provienen de textos literarios.)

Hasbum, Michel

1970 Dichos y aforismos, La Moda de París, Tegucigalpa, 50 pp.

Heraldo, El

1988 "Abril: el mes de! idioma", El Heraldo, Tegucigalpa, 19 de abril, n. 9.

(Es un editorial donde se señala el descuido en la enseñanza y difusión del español en Honduras. Presenta dos expresiones incorrectas y propone, para paliar el problema, la creación de un Instituto Pro-defensa y Rescate del Idioma.)

Hernández, Aurora E. y Melba J. Rivera

1971 El uso de los sufijos en el habla hondureña, tesis de Profesor en Educación Media en Letras, Escuela Superior del Profesorado "Francisco Morazán", 41 pp.

(En su parte central registran, partiendo del uso, los sufijos -era, -ero, -al, -ina, -río, -ada, -oso, -udo, -eco, -ón, -illa y -encia, como los más usuales. Además, recopilan, sin aparente criterio, expresiones adverbiales, piropos, apodos, voces relacionadas con la cantina y el trago, expresiones amorosas, comidas, características físicas de las personas y sinónimos de cárcel. El trabajo no señala ni el número, ni nombre de los informantes, ni el lugar de procedencia.)

Herranz, Atanasio

1983 "Alberto Membreño y la lexicografía en Honduras", en Español. 'Antologia, Guaymuras, Tegucigalpa, pp. 74-89.

(Describe la obra y la formación académica de A. Membreño. Señala su gran labor y algunos errores al considerar la etimología de algunos prefijos y sufijos indígenas. Termina mostrando la gran deuda que tienen con Membreño todos los diccionarios y vocabularios de hondureñismos posteriores.)

1984 "El léxico del habla de Guajiquiro", tesis de Licenciatura en Filología Románica, Universidad Complutense de Madrid, 201 pp.

(Trata de mostrar algunos efectos del contacto durante varios siglos de la lengua lenca, náhuatl y castellana en esa comunidad. Se presentan tres nuevos vocabularios del lenca de Guajiquiro, haciéndose algunas observaciones fonológicas y léxicas. Se muestra, posteriormente, el grado de conocimiento pasivo de cuatro informantes de una muestra de trescientos noventa y un palabras náhuas usuales en Honduras. Termina con una cala léxica sobre "insectos, pájaros y animales salvajes". El cuestionario se aplicó a veinticuatro informantes de distintas edades y sexos, analizándose la incidencia actual del español, náhuatl y lenca en dicho campo léxico.)

Instituto Departamental de Occidente

1956 "Hondureñismos: La Esperanza, departamento de Intibucá", $B A H o$, 2 (2), 128-130. 
(Muestra el significado de cincuenta y tres voces. En algunas de ellas se indica que es indígena, sin especificar la lengua de procedencia.)

Instituto Departamental "Francisco J. Mejía"

1956 "Hondureñismos: Olanchito, departamento de Yoro", BAHo, 2 (2), 134-138.

(Tiene noventa y nueve entradas con sus respectivos significados.)

Instituto Departamental "La Fraternidad"

1956 "Hondurem̄ismos: Juticalpa, departamento de Olancho", $B A H o, 2$ (2), 123-127.

(Registra, sin orden alfabético, ciento cuatro palabras y expresiones.)

Instituto Departamental "La Independencia"

1956 "Algunos vocablos y modismos usados en el departamento de Santa Bárbara", BAHo, 2 (2), 139-141.

(Incluye sesenta palabras y tres modismos.)

Instituto Geográfico Nacional

1976 Dïcionario geográfico de Honduras: departamento de Atlántida, Instituto Geográfico Nacional de Honduras, Tegucigalpa, 116 pp.

1976 Nombres geográficos de Honduras: departamento de Atlántida, Instituto Geográfico Nacional de Honduras, Tegucigalpa, $33 \mathrm{pp}$.

1977 Nombres geográficos de Honduras: departamento de Cortés, Instituto Geográfico Nacional de Honduras, Tegucigalpa, $47 \mathrm{pp}$.

1980 Nombres geográficos de Honduras: departamento de Copán, Instituto Geográfico Nacional de Honduras, Tegucigalpa, $60 \mathrm{pp}$.

1981 Nombres geográficos de Honduras: departamento de Comayagua, Instituto Geográfico Nacional de Honduras, Tegucigalpa, $60 \mathrm{pp}$.

1982 Nombres geográficos de Honduras: departamento de Islas de la Bahía, Instituto Geográfico Nacional de Honduras, Tegucigalpa, $26 \mathrm{pp}$.

1982 Nombres geográficos de Honduras: departamento de Choluteca, Instituto Geográfico Nacional de Honduras, Tegucigalpa, $85 \mathrm{pp}$.

1984 Nombres geográficos de Honduras: indice-departamento de Francisco Morazán, Instituto Geográfico Nacional de Honduras, Tegucigalpa, 166 pp.

(Se incluyen los pueblos y aldeas más importantes de cada departamento y se señalan datos geográficos, demográficos e históricos. No incluyen, salvo el primero, la etimología de los topónimos.)

Instituto "Ramón Rosa"

1956 "Hondureñismos: Gracias, departamento de Lempira", BAHo, 2 (2), 131-133.

(Explica el significado de cuarenta y seis palabras y expresiones. Algunas de ellas ya las había registrado J. CisNeros en sus Hondureñismos.)

IZAGUiRre, Carlos

1955 "Hondureñismos: vocablos, giros y locuciones más corrientes usadas en Honduras", BAHo, 1 (1), 59-123. 
(Tiene un total de mil trescientas nueve entradas. En cada artículo señala su categoría gramatical y su significado. A veces, indica la etimología y los aspectos morfológicos de género, número, derivación y, en los verbos, si son transitivos o intransitivos. Le debe mucho a Hondureñismos de MEMBREÑO.)

Kany, Charles E.

1945 American-Spanish syntax, $2^{\text {a }}$ ed., University of Chicago, Chicago, 1951.

1976 Sintaxis hispanoamericana, Gredos, Madrid, 551 pp.

(Aparecen algunas referencias sobre el español de Honduras. Éstas son: el sustantivo y su número, pp. 23, 25-27; el adjetivo, pp. 5759, 67-71; el voseo, pp. 80 y 113-114; le indirecto redundante, pp. 139140 ; lo $d e=$ 'casa de', pp. 163-164; uso de que por 'a quien', pp. 166167; uno como indefinido, pp. 177-178; locuciones en presente por el futuro, p. 192; vamos por vayamos, pp. 215-216; imperfecto de subjuntivo o de deseo, pp. 223-224; locuciones verbales, pp. 247-248; verbos auxiliares, pp. 249-252, 255-256, 258-260, expresiones como cada manada, al tiro, de pie, de viaje, al no más, pp. 326, 335, 352, 357, 371; uso de preposiciones, pp. 391, 401, 426, 428-432 y las interjecciones, pp. 472, 487, 502. Los ejemplos del español de Honduras provienen de textos literarios.)

1945 American-Spanish semantics, $2^{\text {a }}$ ed., University of Chicago, Chicago, 1951.

1969 Semántica hispanoamericana, Aguilar, Madrid, 298 pp.

(Incluye un buen número de hondureñismos tomados de la literatura y del diccionario de Membreño.)

KLEIN, EARL H.

1977 Mamíferos de Honduras, Ministerio de Recursos Naturales, Tegucigalpa, $91 \mathrm{pp}$.

(Estudia cuarenta y tres animales comunes en Honduras. Incluye dibujos de cada animal.)

LANDA, LuIS

S.f. Aves regionales de Honduras, Imp. López, Tegucigalpa, 47 pp.

(Registra cincuenta y ocho clases de aves, agrupándolas en ocho familias. Señala los nombres comunes, el científico y su hábitat.)

Landa, Luis y Ramón Montoya

1940 Lista de maderas y plantas medicinales hondureñas, Imp. Calderón, Tegucigalpa, 25 pp.

(Muestra el nombre común, nombre científico y la familia a la que pertenecen doscientas cincuenta variedades de árboles y ciento noventa y ocho plantas y raíces.)

LARDÉ Y LARÍN, JORGE

1943 "La raíz carán, carrán y cayán", Revista del Archivo y de la Biblioteca Nacional, (12), 816-817; (20), 41-44; (21), 105-109.

1943 "Significado del nombre Lempira", Revista del Archivo y de la Biblioteca Nacional, 22 (4), 239-240. 
1944 "La raíz güia, cuina o quina", Revista del Archivo y de la Biblioteca Nacional, $22(7), 419-423$.

1944 "Significado del nombre Tegucigalpa", Revista del Archivo y de la Biblioteca Nacional, 22 (10), 631-635.

1951 "El vocablo cachureco; su origen y etimología", Revista del Archivo y de la Biblioteca Nacional, 29 (9-10), 413-416.

1952 "El verdadero origen de la palabra catracho", Revista del Archivo y de la Biblioteca Nacional, 29 (11-12), 496-497.

LEHMANN, WALTER

1920 Zentral-Amerika, 2 ts., Berlín.

(En el t. 2, pp. 624-625, 671-682, incluye un amplio vocabulario lenca y explica el significado de muchos topónimos lencas de Honduras. A. ChAPMAN retomó esta información en su obra Los lencas de Honduras en el siglo XVI, p. 38.)

LIPSKI, JOHN M.

1983 "Reducción de /s/ en el español de Honduras", NRFH, 32 (1983), 272-288.

1983a " $S$ in Central America". Aparecerá en $H$.

1987 * Fonética y fonología del español de Honduras, Guaymuras, Tegucigalpa, $144 \mathrm{pp}$.

(Es un estudio global de la fonología del español de Honduras desde la teoría de la fonología natural. Analiza todas las vocales y las consonantes. Enfatiza en el análisis de la $/ \mathrm{s} /, / \mathrm{n} /$ y los factores silábicos. De los grupos consonánticos sólo investiga /ng/. En esta obra incorpora parte del trabajo de la "Reducción de /s/ en el español de Honduras".)

Lope Blanch, Juan M.

1968 El español de América, Alcalá, Madrid, $150 \mathrm{pp}$.

(Valora los principales trabajos sobre el español de América. En el apartado de Honduras sólo cita los trabajos lexicográficos de C. Izaguirre y F. Figueroa.)

López, César Francisco

1955 "Hondureñismos usados en el departamento de Lempira", $B A H o, 1$ (1), 139-140.

(Presenta treinta entradas con sus respectivos significados.)

López Pineda, Julián

1914 "El idioma ispanoamerikano", Ateneo de Honduras, 2 (10), 308-310.

1955 "Origen y evolución del castellano", BAHo, 1 (1), 15-26.

López Scott, Alma Leticia

1983 A sociolonguistic analysis of /s/.variation in Honduran, tesis de Ph. D., University of Minnesota.

(No ha sido posible consultarla.) 
Lunardi, Federico

1941 "Etimología de la palabra Lempira", Revista del Archivo y de la Biblioteca Nacional, 22 (2), 115-117 y 23, (9), 561-591.

Martínez López, Eduardo

1906 "Provincialismos y barbarismos de Honduras", Revista del Archivo y de la Biblioteca Nacional, 2 (14), 435-440.

(Incluye ciento cincuenta y cuatro voces. A la par del hondureñismo señala la palabra utilizada en el español estándar. El estudio de este listado aporta interesantes datos sobre la pronunciación del español de Honduras.)

Mejía, Medardo

1964 "Defensa del idioma legal”, Ariel, 6 (154), p. 1.

Membreño Márquez, Alberto

1895 Hondurcñismos. Vocabulario de los provincialismos de Honduras, Tipografía Nacional, Tegucigalpa, $123 \mathrm{pp}$.

(Tiene mil doscientas sesenta y tres palabras y expresiones y un suplemento de setenta y siete hondureñismos recogidos por 1gnacio Fiallos, colaborador de Membreño. Para una crítica de esta edición consúltese R. Menéndez Pidal.)

1897 Hondureñismos. Vocabulario de los provincialismos de Honduras, $2^{\mathrm{a}}$ ed. Tipografia Nacional, Tegucigalpa, $270 \mathrm{pp}$.

(En esta segunda edición, el autor incrementó notablemente el número de entradas. Para una crítica a esta edición véase J. DE BARCELONA. Como apéndice incluye unos "Breves vocabularios del moreno, zambo, sumo, paya, jicaque, lenco y chortí”, pp. 192-270.)

$1901{ }^{*}$ Nombres geográficos indígenas de la República de Honduras, Tipografía Nacional, Tegucigalpa, xxix $+118 \mathrm{pp}$. También apareció publicado por entregas en la Revista del Archivo y de la Biblioteca Nacional, núms. 13-18, 1934-1939.

(En la introducción incluye el estudio de varios sufijos comunes de la toponimia hondureña. Muestra la influencia de la lengua náhuatl en Centroamérica, recopilando y analizando la procedencia náhuatl de ciento quince topónimos de Guatemala y ciento ocho de Nicaragua. El grueso de la obra lo dedica al estudio etimológico de ochocientos ochenta topónimos de Honduras. Para una crítica véase A. Herranz, 1983.)

1907 Aztequismos de Honduras, Ignacio Escalante, México, 28 pp. Se publicó por entregas hasta la palabra lipigüe en la Revista del Archivo y de la Biblioteca Nacional, 3 (23-24), 757-764; 4 (1-2), 34-36 y 4 (3-4), 118-120.

(El total de entradas es doscientos veintiocho, señala su etimología. Sigue de cerca el Diccionario de aztequismos de Cecilio A. Robelo.)

1908 Nombres geográficos de la República de El Salvador, Ignacio Escalante, México, $53 \mathrm{pp}$.

$1912{ }^{*}$ Hondureñismos, $3^{\mathrm{a}}$ ed., Müller Hermanos, México, 173 pp.

(Ésta es la última edición revisada por A. Membreño. Amplia la segunda e incorpora los Aztequismos de Honduras publicados en 1907. En esta edición no mcorporó el apéndice de "Breves vocabularios..." de la segunda edición.) 
1921 Hondureñismos, $4^{\text {a }}$ ed., Müller Hermanos, México, 173 pp.

(En realidad es una reedición, aunque apareció como una nueva edición.)

1967 "Nombres geográficos indígenas de Honduras: departamento de Olancho", Anales del Archivo Nacional, 1 (2), 6-9.

1968 "Nombres geográficos indígenas de Honduras: departamento de Santa Bárbara", Anales del Archivo Nacional, 2 (3), 9-11.

1969 "Nombres geográficos indígenas de Honduras: departamento de Francisco Morazán", Anales del Archivo Nacional, 3 (6), 16-26.

1970 "Nombres geográficos indígenas de Honduras: departamento de Copán", Anales del Archivo Nacional, 4 (8), 12-15.

(Todas las publicaciones de los nombres de los departamentos de Olancho, Santa Bárbara, Francisco Morazán y Copán son una selección hecha por la revista Anales del Archivo Nacional de la obra de A. Membreño Nombres geográficos indígenas de la República de Honduras.)

1982. Hondureñismos, $5^{\mathrm{a}}$ ed., Guaymuras, Tegucigalpa, $233 \mathrm{pp}$.

(En el libro se señala erróneamente que es la tercera edición, siendo realmente la quinta. El texto de Hondureñismos de esta edición se tomó de la segunda y no de la tercera, que es la más completa. Se incluyó como apéndice Hondureñismos de Jeremías Cisneros, colaborador de A. Membreño, y publicados por entregas en 1907 en la Revista del Archivo $y$ de la Biblioteca Nacional.)

Mencía, EnRiQue

1971 Dichos y refranes populares, Imp. Cultura, Comayagüela, $42 \mathrm{pp}$.

\section{MenÉndez Pidal, Ramón}

1896 * "Hondureñismos de Membreño: nota crítica", Revista Crítica de Historia y Literatura Españolas, Portuguesas e Hispanoamericanas, 1, p. 75.

(Menéndez Pidal alaba la obra de Membreño por recopilar palabras del español que habían caído en desuso en España. Le señala que incluye como hondureñismos neologismos que se usan en España con igual significado. Entre ellos cita contrabandear, editar, emocionarse, emperifollarse, enraizar, ilusionarse, holán, indino, ingüete, interfecto, hotel, jambar, juma, maturranga, etc. Además le indica que no son hondureñismos: alcancia, barbasco, cantina, embarrar, gallinero, gradilla, inscribir, lazar, liso, etc.).

Nelson Sutherland, Giryl Hardy

1986 Plantas comunes de Honduras, 2 ts. Universidad Nacional Autónoma de Honduras, Tegucigalpa.

(Es el estudio de flora hondureña más completo. El t. 1 incluye: una introducción fisiográfica de Honduras, descripción de los herbarios existentes en el país e inicia el estudio de las plantas más comunes. El t. 2 está dedicado, en su parte central, a concluir el estudio de las plantas. Señala los nombres comunes de cada una de ellas, el nombre científico, la familia a que pertenece, una amplia descripción de tallos, hojas y frutos y un dibujo de todas o alguna de sus partes. Este segundo tomo finaliza con una lista de nombres de plantas en lengua miskita.) 
Nieto, Elba María

$1986{ }^{*}$ Léxico del delincuente hondureño. Diccionario y análisis lingüístico, Universidad Nacional Autónoma de Honduras, Tegucigalpa, 216 pp.

(En la primera parte analiza los conceptos de "germanía" y "germanía hondureña". En la segunda presenta un amplio número de palabras utilizadas por los distintos tipos de delincuentes. Las listas se presentan por actividades: robo, monedas, cuerpo humano, armas, etc. Termina el trabajo señalando la metodología utilizada en la recolección y en el análisis de los datos.)

Nuila, Ramón W., T. Humberto Salinas $e t$ al.

1987 "Informe de la investigación exploratoria inicial en las agencias de desarrollo de San Luis, San Jerónimo y El Rosario, departamento de Comayagua", Secretaría de Recursos Naturales, Tegucigalpa, 32 pp. (mimeo.)

(Es una investigación exploratoria hecha por agrónomos y extensionistas para conocer el vocabulario de esas tres comunidades. Incluye doscientas treinta y ocho palabras, señalando en la mayoría su significado. Después presentan treinta y siete expresiones recogidas en San Jerónimo. Finaliza el informe con sesenta y cinco palabras recogidas en El Rosario. Trabajo empírico.)

OQuelí, Ramón

1983 "Provincialismos y dos señores de antaño", diario El Tiempo, San Pedro Sula, 19 de enero, pp. 6 y 36.

(A raíz de la publicación de Hondureñismos por la editorial Guaymuras, Oquelí presenta, en este artículo, algunos datos biográficos de A. Membreno y J. Cisneros.)

Palma Juárez, Juana

1967 El refrán en Honduras, tesis de Profesor en Educación Media en Letras, Escuela Superior del Profesorado "Francisco Morazán".

Pérez Cadalso, Eliseo

1987 "Su señoría, el idioma", El Heraldo, Tegucigalpa, 26 de agosto, pp. 8 y $52 ; 27$ de agosto, pp. 8 y $49 ; 28$ de agosto, pp. 8 y 42 .

(Señala el debilitamiento de la norma culta en Honduras y como consecuencia se dan, incluso entre gente culta, confusiones semánticas entre palabras próximas en su significado o parecidas en su estructura fonética. Entre las confusiones señala: contrabando y defrudación; querella, denuncia y delación; chantaje y extorsión; violación y estupro; inflingir e infringir y deleznable y condenable.)

1988 "Hachazos contra el lenguaje", El Heraldo, Tegucigalpa, 29 de abril, p. 8.

(Señala algunos vicios en el uso del lenguaje tales como: discordancia entre artículos y nombres, confusión de significados de palabras, metátesis y epéntesis.)

Pineda Urbina, Elsa, Enna O. Benítez y Rebeca Guzmán

S.f. Aumentativos y diminutivos usados por los estudiantes de primer curso del ciclo 
común de Cultura General de Ocotepeque y Olanchito, tesis de Profesorado en Educación Media en Letras, Escuela Superior del Profesorado "Fran" cisco Morazán", $130 \mathrm{pp}$.

(Se analiza el uso de aumentativos y diminutivos de ciento cincuenta jóvenes de trece a quince años. Setenta y cinco de la ciudad de Olanchito, departamento de Yoro, y el resto de la ciudad de Ocotepeque, cabecera del departamento del mismo nombre, fronterizo con Guatemala y El Salvador. A través de una encuesta directa se investigó el uso de aumentativos de diez nombres y adjetivos y los diminutivos de ventidós sustantivos y adjetivos. Después analiza la capacidad creadora en aumentativos y diminutivos. La tesis concluye con el análisis cuantitativo de los diminutivos de nueve nombres propios de personas, llegándose a una conclusión satisfactoria.)

Ponce Aceituno, Gladys

1985 Determinación de la extensión territorial del pueblo lenca a partir de la toponimia, tesis de la Licenciatura en Lingüística, Universidad Nacional Autónoma de Honduras, 91 pp.

(Trata de delimitar la antigua área lenca de Honduras a partir de algunos topónimos. Además, incluye una lista de topónimos mayas y náhuas.)

Ponce Aceituno, Nolvia D.

1985 Indigenismos en el habla de Guajiquiro, tesis de Licenciatura en Lingüística, Universidad Nacional Autónoma de Honduras, 87 pp.

(Presenta una lista de indigenismos caribes, náhuas, lencas y mayas utilizados en el habla de Guajiquiro, departamento de La Paz. La recolección de datos la hizo aplicando un cuestionario léxico a veinticuatro informantes. El cuestionario fue una adaptación del Atlas lingüistico y etnográfico de Andalucía. No presenta los resultados de todo el cuestionario y de todos los informantes por lo que nos priva de una visión global del léxico de la comunidad e impide conocer el peso específico de los indigenismos, en especial los de procedencia lenca.)

Revista del Archivo y de la Biblioteca Nacional

1949 "Inauguración de la Academia Hondureña de la Lengua el 28 de diciembre de 1948", 27 (7-8), 337-340.

Reyes-Mazzoni, Roberto

1975 "El nombre de Olancho y los grupos de habla náhuatl en Honduras", BAHo, 18 (18), 43-50.

Rivas, Pedro

1930- "Diccionario geográfico, histórico y etimológico de Honduras"', Revis-

1934 ta del Archivo y de la Biblioteca Nacional, 9 (6-12), 177-180, 207-210, 232234, 262-264, 296-299, 328-330; 10 (1-3), 10-11, 46-50, 87-90, 162-164; 10 (5-12), 162-164, 212-216, 278-280, 342-344, 389-392; 11 (1-11), 14$16,79-82,125-128,179-180,223-226,278-280,342-344,389-392 ; 12$ (1-3), 14-16, 79-82, 125-128, 179-180, 223-226, 270-272, 318-320, 383- 
$386,438-440 ; 12(5-8), 18-20,84-86,153-154,281-282,344-345,411-$ 412 y $491-492$.

(Incluye topónimos, hechos y personajes de la historia de Honduras. Señala la etimología de la mayoría de topónimos coincidiendo, por lo general, con A. Membreño.)

ROSA, RAMÓN

1977 "Diccionario de centroamericanismos", Revista de la Universidad Nacional Autónoma de Honduras, 6 (13), 67-78.

(El manuscrito se conserva en la biblioteca de la Universidad Nacional Autónoma de Honduras. Está fechado en la significativa fecha del 12 de octubre de 1886, Alajuela, Costa Rica. Contiene palabras y expresiones de los países centroamericanos. La obra, apenas la inició el autor. Sólo incluye cuarenta y cinco entradas, de la A hasta ACHUMICADO. En cada artículo señala el significado, acepciones, países y contextos literarios o coloquiales en que se usa el término.)

Rosa, Tobías J. M.

1918 Flora y fauna santabarbarense, Tipografía Nacional, Tegucigalpa, 73 pp.

(Presenta doscientas veintisiete plantas y ciento nueve vertebrados y mamíferos comunes en ese departamento.)

Salazar G., Salomón

1908 Diccionario de vicios y corrupciones del idioma español, Tipografia Nacional, Tegucigalpa.

Salgado de Rivera, Mariana

1984 Actualmente la lengua lenca en el léxico de Guajiquiro es de substrato, tesis de Licenciatura en Lingüística, Universidad Nacional Autónoma de Honduras, $88 \mathrm{pp}$.

(Aplicó el cuestionario del Atlas lingüistico y etnográfico de Andalucia con adaptaciones y modificaciones. El cuestionario constaba de 1696 preguntas y estaba dividido en quince apartados. La tesis concluye señalando un reducido número de palabras lencas del total del corpus. Como no incluye todos los resultados de la encuesta no podemos hacernos una idea global del léxico utilizado en esa comunidad, ni del peso de los lenquismos.)

SCAVNicky, Gary E. A.

1974 "Los "sufijos" no españoles y las innovaciones sufijales en el español centroamericano", BICC, 29, 1-52.

(Divide el trabajo en cuatro partes. En la primera realiza un breve estudio de las lenguas y tribus de América Central. Después presenta una serie de voces con desinencias indígenas, africanas o desconocidas. Continúa con un grupo de palabras cuyos sufijos han podido originarse en España o en las lenguas indígenas. La última parte presenta una lista de voces de formación híbrida, raíz indígena y sufijo español. Incluye en todos los grupos un buen número de ejemplos de Costa Rica, Nicaragua, Guatemala, Honduras y El Salvador. Resulta insuficiente la información de las lenguas y tribus de Centroamérica.) 
SCHUlLER, RUdOLF

1930 "Un punto de la lingüística nacional llamada Ilamatepec", Revista del Archivo y de la Biblioteca Nacional, 9 (3), 89-90.

Sevilla, Luis Hernán

1976 El lenguaje del hampa en Honduras, tesis de Licenciatura en Ciencias Jurídicas y Sociales, Universidad Nacional Autónoma de Honduras, 73 pp.

(Recoge palabras y expresiones utilizadas por grupos marginados. Divide el vocabulario en apartados según el grupo o actividad respectiva: timadores, carteristas, asaltantes, ladrones, rateros, fumadores de marihuana, presos, etc. Para cada palabra señala significado y categoría gramatical. No incluye los contextos en que se usan los vocablos y expresiones.)

1981 "Folklore lingüístico del habla hondureña", diario El Tiempo, San Pedro Sula, 14 de diciembre, pp. 6 y 35.

(Recoge y comenta veinticinco refranes y dichos populares comunes en Honduras.)

Sierra Valladares, Pedro

1919 Guia para facilitar la enseñanza del castellano en las escuelas de los lugares donde se habla el dialecto mosco, Tipografía Nacional, Tegucigalpa, 24 pp.

(Da algunos datos sobre la campaña de enseñanza del español en la Mosquitia y presenta un vocabulario y frases en miskito-español.)

Sorto de Rivera, Ana Ruth

1970 La fonética en los programas de español en educación media, tesis de Profesor en Educación Media en Letras, Escuela Superior del Profesorado "Fran" cisco Morazán", 42 pp.

(Presenta algunos contenidos y actividades que deben incorporarse a los programas de español en educación media. Transcribe fonéticamente algunas frases, señalando la actividad que realiza el informante en la vida diaria. Presenta, más adelante, unos ejercicios para evitar los errores más comunes del habla hondureña. Señala los siguientes: cambio de posición del acento; cambio de timbre de algunas vocales $e>i, o>u$; reducción a un solo fonema de los grupos consonánticos $/ \mathrm{ct} /, / \mathrm{pt} /, / \mathrm{ns} / \mathrm{y} / \mathrm{mn} /$; uso incorrecto del artículo y cambio de algunas consonantes por otras.)

Valladares, Paulino

1973 "Doctor Alberto Membreño", Foro Hondureño, 39 (2), 3-4.

Valladares Lanza, Manuel

1970 "Caliche o caló. Apuntes para el estudio de la criminología hondureña", Anales del Archivo Nacional, 4 (8), 88-95.

(Divide el artículo en tres partes. En la primera presenta una lista caliche-castellano con trescientas una entradas. La segunda incluye doscientas cinco voces del castellano-caliche. Termina mostrando cuarenta y dos refranes y expresiones jergales.) 
Valle, Rafael Heliodoro

1943 "Etimología de Tegucigalpa", Revista del Archivo y de la Biblioteca Nacional, 21 (12), 801-812.

1952 "El español de la América española", Revista del Archivo y de la Biblioteca Nacional, 31 (1-2), 67-74. También se publicó en 1953 en $H, 36,52-57$.

1959 "Nombres españoles de Honduras", BAHo, 5 (6), 105-107.

(Presenta una lista de las primeras ciudades fundadas por los españoles en Honduras y hace algunas observaciones lingüísticas sobre los nombres compuestos, primer nombre español y segundo nombre indígena.)

Valle de Martínez Pavetti, Elisa

1976 El vocabulario del escolar, Departamento de Pedagogía y Ciencias de la Educación, Universidad Nacional Autónoma de Honduras, Tegucigalpa, 233 pp.

(Es un estudio del léxico escolar en trece centros educativos de Tegucigalpa. Se aplicó un cuestionario organizado según veinte centros de interés. Se investigaron los sustantivos, adjetivos y verbos más usados. En cada una de las categorías gramaticales se analizan aspectos de género y número, y en los verbos los tiempos. Al final presenta una lista por cada categoría gramatical indicando su frecuencia.)

Vallejo, Antonio R.

1906 Ligeras observaciones al "Curso elemental de la lengua española" publicada en El Salvador, Tipografía Nacional, Tegucigalpa, xi $+419+$ iii pp.

(Esta voluminosa obra contiene, como señala su autor, una serie de observaciones y ampliaciones al Curso elemental de historial de la lengua española de Ignacio Barberena. Tiene diecisiete capítulos que abarcan desde los orígenes del lenguaje, la clasificación de las lenguas y su evolución hasta un análisis de la lengua castellana. Es una muestra interesante de las teorías sobre el origen del lenguaje y la procedencia de las lenguas europeas.)

1913 “Réplica a Santiago I. Barberena”, Revista de la Universidad, 5 (3), 137-148.

VAN WIJK, H. L.

1966 "Los gentilicios hondureños" en Homenaje a Van Goor Zonen, Instituto de Estudios Hispánicos, Portugueses e Iberoamericanos, La Haya, pp. 593-603.

(Estudia los gentilicios de ciento treinta ciudades, villas y pueblos de todos los departamentos de Honduras. Los sufijos más frecuentes en los gentilicios hondureños son: -eño, 74 lugares (57\%); -ense 29 lugares $(22.3 \%)$; -ano, 15 lugares $(11.5 \%)$; -eco, 5 lugares (3.9\%), etc. Señala que los hondureños no son muy dados a utilizar gentilicios en la conversación.)

1968 * "Algunos aspectos morfológicos y sintácticos del habla hondureña", $B d F S, 20$ (1), 3-16.

(El propio autor resume, al final de su trabajo, las características más notorias del habla hondureña. Éstas son: "construcciones con nu- 
merosos arcaísmos; uso mayoritario de los sufijos -ada, -al, -ero, -era, -ón, -(a)zón y -dera; utilización adverbial del adjetivo; uso de perífrasis con ir + gerundio; uso popular del diminutivo -illo asociado con -ito en adjetivos y adverbios; el empleo del sufijo náhuatl -eco para gentilicios y en la formación de adjetivos despectivos que indican defectos; el uso del vos, etc'. Es el estudio más completo del plano morfosintáctico del habla hondureña.)

WAGNER, MAX LEOPOL

1950 "El sufijo hispanoamericano -eco para denotar defectos físicos y morales", NRFH, 4, 105-114.

(M. L. Wagner sostiene que el sufijo -eco proviene del náhuatl. Presenta una lista de palabras, que en el caso de Honduras, las toma de A. Membreño. J. M. Lope Blanch y Jorge A. Suárez dudan de la procedencia náhuatl del sufijo y creen que proviene del español. Cf. J. M. LOPE BLANCH, "Sobre el origen del sufijo -eco, como designador de defectos" en Estudios sobre el español de México, UNAM, México, 1972, pp. 165-174 y JORGE A. SUÁREZ, "Indigenismos e hispanismos, vistos desde la Argentina”, $R P h, 20,1966,68-90$, especialmente pp. 87-89.)

Walz, Thomas $\mathrm{H}$.

1964 Favorite idioms and expressions used in Honduras, s.e., Tegucigalpa, 141 pp.

(Como el propio autor señala en la introducción, este diccionario se elaboró como una ayuda para empleados del gobierno norteamericano, estudiantes, misioneros y voluntarios del Cuerpo de Paz que vienen a Honduras y necesitan aprender el español. El diccionario contiene los siguientes apartados: lista de palabras más usadas en Honduras, español-inglés; lista de categorías idiomáticas, inglés-español; palabras de uso común que son tabú, español-inglés; selección de recibimientos cortos, saludos y observaciones, español-inglés, y gestos de cuerpo y manos más utilizados.)

Weitnaver, Isabel e Isabel Guillén de Dios

1964 La enseñanza de la gramática en la escuela primaria, Ministerio de Educación Pública, Tegucigalpa, $134 \mathrm{pp}$.

WOODBRIDGE, THOMAS $\mathrm{H}$.

1956 "Central American Spanish. A bibliography (1940-1953)", Revista Interamericana de Bibliografía, 6 (2), 103-105.

(De Honduras cita la obra de Florencio Alvarado, Folklore nacional: caló hondureño, vulgarismos.)

Zabala, Rosalío y Libardo Hoyos Cardona

1964 Diccionario escolar de la lengua española. (A péndice: Hondureñismos), $5^{\mathrm{a}}$ ed., Stella, Bogotá, pp. 345-449.

(La primera parte es un diccionario escolar elaborado por Libardo Hoyos Cardona. La segunda parte es un diccionario de hondureñismos escrito por Rosalío R. Zabala. Tiene, aproximadamente, dos mil quinientas entradas. A cada entrada le señala su categoría gramatical 
y explica su significado. En algunas voces incluye, como ejemplo, una frase coloquial o literaria.)

Zapata, Roberto

1986 "Cuestiones sobre el habla hondureña", Presente, Tegucigalpa, 2 (108109), 3-9.

(Trata cuestiones generales de la lengua y del español de América. Finaliza con algunas cuestiones sobre la nahuatlización del español de Honduras.)

Zelaya, Gisele, Marta Luz Cabrera et al.

1982 Reseña bibliográfica sobre el español de Honduras, Carrera de Letras, Universidad Nacional Autónoma de Honduras, Tegucigalpa, 21 pp. (mimeo.).

(En una breve introducción se señalan los propósitos del trabajo y la metodología utilizada. Presenta a continuación cuarenta y ocho fichas bibliográficas con descripción del contenido de cada obra. Termina con conclusiones sobre la bibliografía del español de Honduras. Este trabajo se realizó en el Seminario sobre el Español de Honduras, dirigido por la licenciada Ada Luz Pineda de Gálvez.)

ZÚNĩga LANDA, ERnesto

1966 Modismos y refranes usados en Honduras. Español-inglés, s.e., Tegucigalpa. 